Informal Report

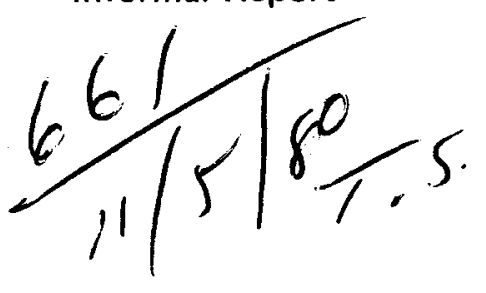

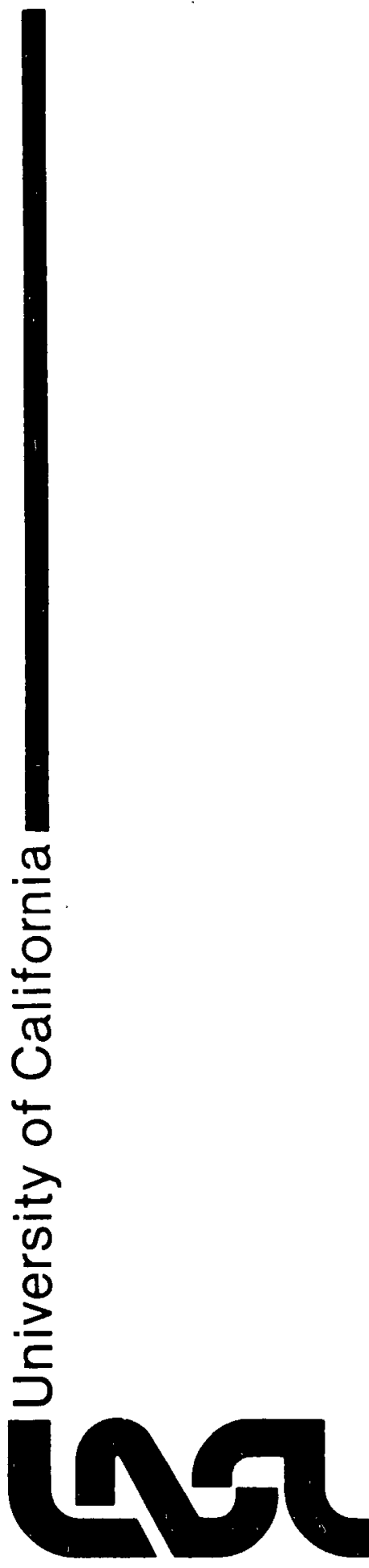

\title{
The Pressure Transient Testing of a Manmade Fractured Geothermal Reservoir: An Examination of Fracture Versus Matrix Dominated Flow Effects
}

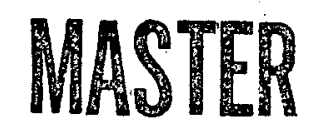


An Affirmative Action/Equal Opportunity Employer

This report was not edited by the Technical Information staff.

This work was supported by the US Department of Energy, Division of Geothermal Energy.

This report was prepared as an actount of work sponsored by an agency of the United States Government. Neither the United States Governinent nor any agency thereof, nor any of their employetes, makes any warranty, express or implied, or assumes any legal liability or Icsponsibility for the accuracy, completeness, or usefulness of any information, apparatus, product, or process disclosed, or represents that its use would not infringe privately owned rights. Reference herein to any specific commercial product, process, or service by trade name, trademark. manufacturer, or otherwise, does not necessarily constitute or imply its endorsement, recommendation, or favoring by the United States Government or any agency thereof. The views and opinions of authors expressed herein do not necessarily state or reflect those of the United States Government or any agency thereof. 
LA-8535-MS

Informal Report

UC-66b

Issued: September 1980

\title{
The Pressure Transient Testing of a
}

\section{Manmade Fractured Geothermal Reservoir:}

\section{An Examination of Fracture Versus Matrix Dominated Flow Effects}

\author{
Henry N. Fisher \\ Jefferson $W$. Tester
}
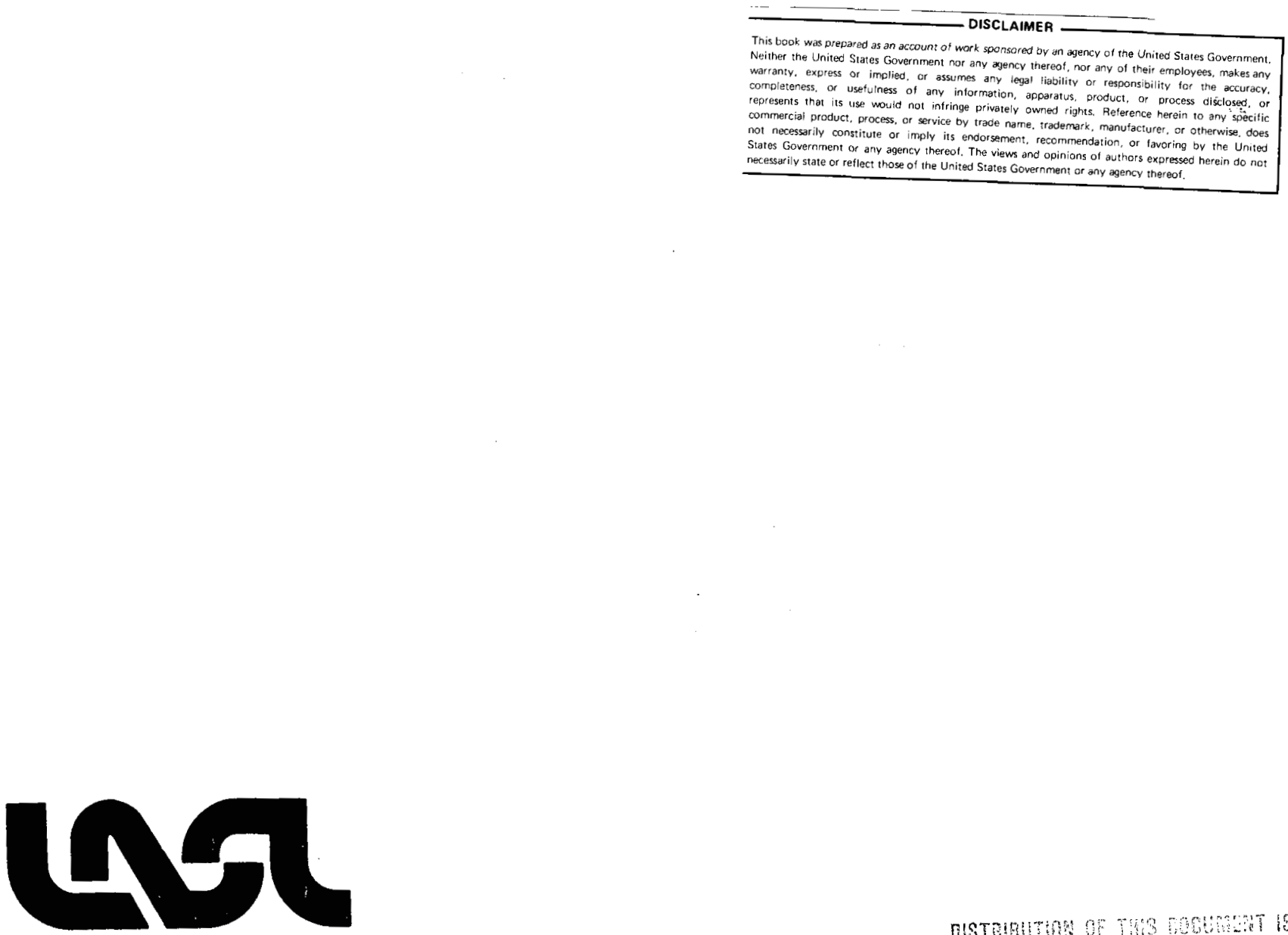


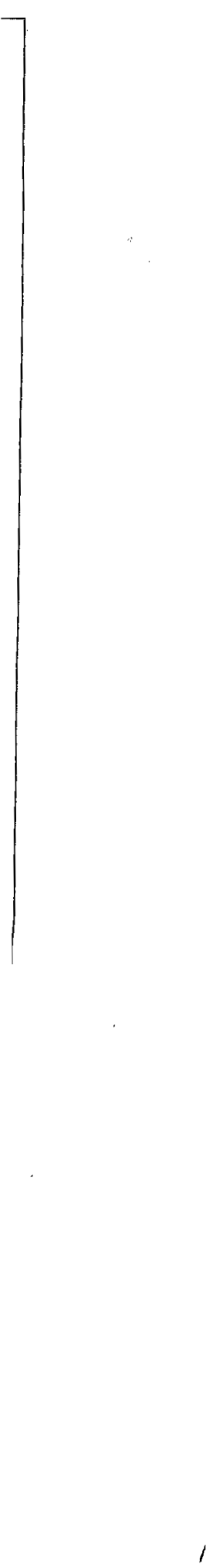


THE PRESSURE TRANSIENT TESTING OF A MANMADE FRACTURED GEOTHERMAL RESERVOIR: AN EXAMINATION OF FRACTURE VERSUS MATRIX DOMINATED FLOW EFFECTS

by

Henry N. Fisher

Jefferson W. Tester

\begin{abstract}
The Los Alamos Hot Dry Rock (HDR) geothermal reservoir system consisting of hydraulic fractures connecting two well lbores was first established in October 1975 at the Fenton Hill site in north-central New Mexico. The fracture system, which is located in crystalline rock at a depth of approximately $2900 \mathrm{~m}$, has been altered since then by two redrilling operations and subsequent hydraulic fracturing attempts. Many experiments involving the pressurization of one or both boreholes have al so altered the flow characteristics of the system. These tests have continued to provide information on the permeation flow into the surrounding formation, the properties of the reservoir rock, the geometry and extent of the main fractures, and the flow-through properties of the heat-exchange paths.

As in the analysis of conventional reservoirs, the data analysis is in terms of a diffusion equation that determines the flow of water and hence the pressure in the main fracture system, associated joints, and the matrix permeability. The fits of the flow data to type curve solutions of the diffusion equation with pressure-dependent properties for various flow geometries are presented. The following points are considered in detail. (1) The limits on the fracture geometry, aperture, and diffusing areas are determined from the diffusion parameters. (2) Dependence of the parameters (impedance, diffusivity) of the flow-through systems are related to the inflation of the major fractures. (3) The rock properties are related to the reservoir compressibility and permeability. In particular, laboratory experiments have shown that the properties of all sizes of cracks from large single fractures to the microstructure are
\end{abstract}




\begin{abstract}
pressure dependent if the fluid pressure is near the confining stress. The effects of this pressure dependence on the form of the type curves are included. (4) The competition of flow into the various types of porosity (main fractures, joints, and microstructure) and the effect on the interpretation of type curves are considered. The approach described in this report makes an important departure from conventional pressure-transient reservoir analysis in that pressure-dependent properties. (including matrix and fracture permeabilities and compressibilities and pore porosities) are incorporated into a numerically simulated generation of type curves resulting from one- and two-dimensional diffusion. In addition, the problem of specifying a unique flow geometry where both matrix and fracture-dominated, non-Darcy flow effects are possible is analyzed using a large amount of field and laboratory data in conjunction with a theoretical treatment that reviews the existing state of the art in reservoir mechanics. This includes pore pressure-dependent effective stress concepts as applied to fracture and pore strain laws, roughness induced turbulent flow in fractures, permeability-porosity relationship, and early-and late-time pressure buildup during injection tests.
\end{abstract}

\title{
I. INTRODUCTION
}

The reservoir is shown schematically in Fig. 1. Detailed descriptions of the drilling, fracturing, and testing history are provided in previous reports. ${ }^{1-5}$ Briefly, the chronology is as follows. GT-2 was drilled first to a depth of $2.929 \mathrm{~km}$ and cased to $2.917 \mathrm{~km}$. Hydraulic fracturing experiments produced a fracture system with the main exit from the wellbore at $2.81 \mathrm{~km}$. EE-1 was drilled to a depth of $3.06 \mathrm{~km}$ but did not intercept the main fracture system of GT-2. Two further attempts to obtain a low-impedance connection were made by cementing off and redrilling GT-2A and GT-2B as sidetracked sections out of GT-2 (Fig. 1). Hydraulic fracturing experiments in GT-2A again did not produce the desired impedance. However, GT-2B did produce a. 


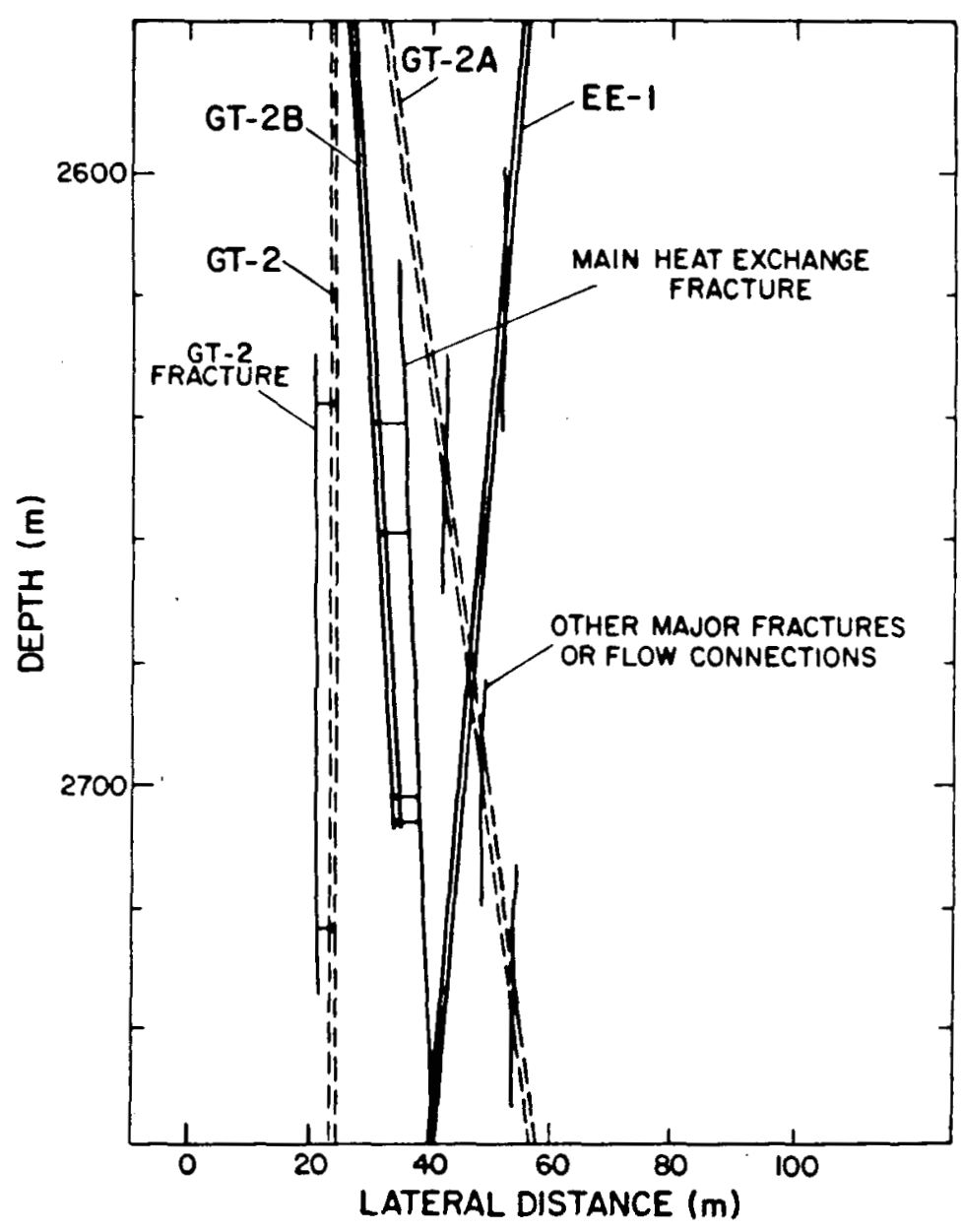

Fig. 1.

Schematic elevation of the Fenton Hill reservoir as of January 1979.

connection with a low enough impedance to permit the long-term heat-extraction and back-pressure tests.

The data available are from two main types of experiments. Injection tests were done on the four wellbores with the other active well shut-in. These consist mainly of constant-flow or step-flow tests; and, the majority were injection into EE-1. They include the attempts at massive hydraulic fracturing. The circulation tests were usually performed by pumping into EE-1 and venting through the active branch of GT-2. The GT-2 well head pressure was most often maintained near zero; the notable exception was the high back-pressure flow tests between EE-1 and GT-2B where the wellhead production pressure was maintained at $\sim 10 \mathrm{MPa}$ (1500 psi). 
Pressurization of the reservoir can result in water storage in or permeation through several different types of pores or fractures.

The small-scale porosity associated with the grain boundaries has been examined in the laboratory..$^{7-9}$ This porosity is of the order $10^{-3}$ and the associated permeability is $10^{-19}$ to $10^{-20} \mathrm{~m}^{2}(0.1$ to $0.01 \mu$ Darcy) at the confining stress encountered in the reservoir.

Considerable natural jointing is observed in the cores and in wellbores. 3,5 These joints have many orientations and a spacing of centimeters to meters. It is possible that these joints can bring the total rock permeability up to $2 \times 10^{-17} \mathrm{~m}^{2}(20 \mu \mathrm{Darcy}) .^{4,5}$ This and the small-scale porosity could be initially homogeneous throughout the reservoir, but there is no certainty, especially for the large-scale jointing. Flow in the naturally occurring porosity may also be anisotropic. The orientation of the large joints is not necessarily isotropic and anisotropic earth stresses can induce anisotropic flow properties in the joint and small-scale porosity.

The naturally occurring porosity and joints can be altered by the pressurization and flow of the system and new fractures can be created. The extent to which altered existing joints and new fractures compete to determine the dominant characteristics of the system is not yet known. However, new fractures are expected to be perpendicular to the minimum earth stress and the existing fractures that are nearly perpendicular to the minimum earth stress are expected to open more readily under pressure and become the dominant flow paths. In any event, the pressurization of the four wellbores produced an extensive, anisotropic, and heterogeneous reservoir. The inflation, and possibly the flow-through characteristics, of the EE-1, GT-2B system were determined in part by the presence of the GT-2 and GT-2A fractures and the connections of these fractures to EE-1.

As in conventional reservoir analysis the model describing the system is based on a diffusion equation for pressure, derived from a Darcy-type flow law and the conservation of mass. The early in situ data ${ }^{4}$ and laboratory experiments on small-scale porosity ${ }^{7-9}$ and on 1arge-scale single fractures ${ }^{10-12}$ necessitated the use of pressure-dependent permeabilities and system compressibilities. This model has provided reasonable fits to the data examined thus far in a number of tests on this reservoir. ${ }^{4-6}$

Under some conditions, the flow laws at high-flow rates for both porous media and fractures can be expected to depend on the flow rate. However, in 
most of the data no strong flow dependence was observed and hence was not needed. That is, Darcy law with a pressure-dependent permeability holds approximately over large flow ranges.

As will be seen later, a systematic analysis of the injection test data indicates some flow dependence in the diffusion parameter that determines the pressure response of the system. This moderate flow dependence contains information on the nature of the system and will be included in future models. A survey of the flow-through impedance data indicates no strong flow dependence until the EE-1 to GT-2B connection was examined at low pressures after the long heat-extraction and high back-pressure (HBP) experiments. The exact nature of the development of this flow dependence has been obscured by the strong pressure dependence of the impedance or by inaccurate flow measurements. At the low flow rates allowed by the high impedance of the early GT-2 to EE-1 connection, no flow dependence was measured. The significance of this flow dependence for the interpretation of the model is discussed below.

Even though the mathematical model provides good fits to much of the data, the diffusion parameters thus measured cannot be interpreted in terms of a unique flow or fracture geometry. From the time of the formation of the first fractures at Fenton $\mathrm{Hill}$, it has been assumed that the early time pressure and flow history of the fracture system were determined by permeation flow out of a large low-impedance (infinite conductivity) main fracture into the surrounding matrix or joints. ${ }^{3,4}$ Considerable evidence now exists that much of the data can be fit with an alternative geometry; that is, flow into and inflation of discrete fractures of high impedance. To determine the degree of competition between matrix and fracture flow we must examine a number of points: (1) the general nature of the type curve fits to the data, (2) the nature of the pressure-dependent rock and fracture properties, (3) the significance of flow-dependent parameters, (4) relationship of the fracture inflation parameters to those governing the flow through the system, and (5) the range of fracture dimensions implied by the diffusion parameters in each case. The objective of this type of analysis is to produce a geometric model of the reservoir consistent with the pressure and flow data. However, even with the aid of other data sets (temperature, seismic, tracer, etc.), it may not be possible to uniquely specify the reservoir. 


\section{I. MATHEMATICAL MODEL}

It is assumed here that the volume flux is determined by the Darcy equation,

$$
\dot{q}=-\frac{k}{\mu} \nabla P,
$$

where $k$ is the permeability tensor, $\mu$ the fluid viscosity, and $P$ the pore pressure. The continuity equation is

$$
\nabla \cdot\left(\rho_{w} \dot{q}\right)+\frac{\partial\left(\rho_{w}^{\phi}\right)}{\partial t}=0 \text {, }
$$

with $\rho_{W}$ the fluid density and $\phi$ the porosity. The pressure then, is the solution to 1

$$
\nabla \cdot \frac{\rho_{W} k}{\mu} \nabla P=\frac{\partial\left(\rho_{\left.w^{\phi}\right)}\right.}{\partial t}=\frac{d\left(\rho_{w}^{\phi)}\right.}{d P} \frac{\partial P}{\partial t} \text {. }
$$

The density of the permeating fluid $\rho_{W}$ can be expanded as $\rho_{W}=\rho_{0}\left(1+c_{W} P\right)$. Then since $c_{w} \backsim 5.0 \times 10^{-4} \mathrm{MPa}^{-1}$ for water

$$
\frac{d\left(\rho_{w}^{\phi}\right)}{d P}=\phi C_{w} \rho_{0}+\rho_{w} \frac{d \phi}{d P} \text {. }
$$

Here, $d \phi / d P$ depends on the properties of the rock, which is 20 times less compressible than water. So it is not clear which term, if either, of Eq. (4) will dominate. Similar considerations hold for the left-hand side of Eq. (3). It will be assumed here that the term $\phi c_{w_{0}} p_{0}$ in Eq. (4) will not dominate and that $\rho_{w}$ can be considered constant. This assumption must be justified later. For now

$$
\nabla \cdot(k \nabla P)=\mu \frac{d \phi}{d P} \frac{\partial P}{\partial t} .
$$


The related quantities $k, \phi$, and $c=d \phi / d P$, and in particular the dependence on pressure cannot be determined exactly since they also depend on the pore volumes, shapes, orientations, and distribution in space, which are not known. In addition, each depends on the three components of stress, which in turn are determined by the in situ earth stresses and, to some extent, the pore fluid pressure.

For the analysis presented here, Eq. (5) is. solved on the computer with the one- or two-dimensional finite element AYER code. ${ }^{13}$ To obtain fits to the in situ data it was necessary to develop empirical fits to the porosity $\phi$, the compressibility $c$, and the permeability $k .{ }^{4,5}$ These empirical expressions al so fit laboratory data on the GT-2 cores reasonably wel1. 9

The porosity is assumed to be controlled by the minimum earth stress $\sigma_{3}$,

$$
\phi=\frac{\phi_{0}^{\star}}{\left[1-C\left(\sigma_{3}+P\right)\right]^{n}} .
$$

The permeability tensor is assumed to have three non-zero components. The two components perpendicular to the least stress are

$$
k_{3}=\frac{k_{0}^{\star}}{\left[1-c\left(\sigma_{3}+P\right)\right]^{3 n}} .
$$

The component parallel to the least stress is

$$
k_{2}=\frac{k_{0}^{*}}{\left[1-c\left(\sigma_{2}+P\right)\right]^{3 n}} \text {, }
$$

where $\sigma_{2}$ is the intermediate stress. The form of $k$ is consistent with the Kozeny-Carmen relation for small porosity, $k \propto \phi^{3} .^{1}$ For the data considered here, $P<S_{3}$ the minimum principle earth stress. For this case it will be seen that the following approximations provide accurate fits to the data.

(a) $\sigma_{3}=S_{3}$, minimum earth stress. 
(b) $\sigma_{2}=S_{2}$, the intermediate earth stress.

(c) $n=0.6$, fits all in situ data.

Then in this case

$$
\begin{aligned}
& \phi=\frac{\phi_{0}}{\left(1-C_{3} p\right)^{0.6}}, \\
& k_{3}=\frac{k_{0}}{\left(1-C_{3} p\right)^{1.8}}, \\
& k_{2}=\frac{k_{0}}{\left(1-C_{2} p\right)^{1.8}},
\end{aligned}
$$

and

$$
\frac{d \phi}{d P}=\frac{\partial \phi}{\partial P}=c=\frac{c_{0}}{\left(1-c_{3} P\right)^{1.6}}
$$

Here,

$$
C_{3}=\frac{C}{1-C_{3}} \text { and } C_{2}=\frac{C}{1-C_{2}} \text {, }
$$

and $\sigma_{0}, k_{0}$, and $c_{0}$ are evaluated at $P=0$.

III. IN SITU DATA FITS

The first detailed computer fits to the Fenton Hill pressure and flow data were produced with AYER. ${ }^{4}$ This produced solutions of Eq. (3) on a twodimensional grid with the pore properties given by Eq. (9). However, it was 
found that two-dimensional effects were not observed. Also, no fiow dependence was included in the flow parameters. Only recently has the role of flow dependence been apparent, after the accumulation of much data. This will be discussed later.

These circumstances have resulted in the specification of a limited number of flow parameters. The inflation data is determined entirely by $\alpha=$ $A \sqrt{k c}$. The time constant for the conversion to multidimension flow $\tau_{A}=A_{\mu c} / k$ has not been measured but lower limits have been obtained. For interference or flow-through tests, the time constant for flow or pressurization between wells, $\tau_{\ell}=\ell^{2} \mu \mathrm{c} / \mathrm{k}$ and the flow impedance $\mathrm{I}=\Delta \mathrm{P} / \dot{Q}=\ell \mu / A K$, are determined. The discussion of how the fracture or rock properties determine these parameters is deferred until later. For now we examine the data fits that determine the magnitudes and pressure-and flow-dependences.

\section{A. Pressure, Buildup, and Injection Testing}

The first group of experiments to be compared to the diffusion model with pressure-dependent properties is described in detail in Ref. 4. Figures 2 and 3 show results from typical early experiments performed in EE-1 and GT-2.

Experiment 111 (Figs. 2 and 3 ) is described in more detail in Refs. 2, 3 , and 4. It consisted of a pressurization of EE-1 in steps, in constant flow and constant pressure phases (upper curve of Fig. 2). The flow and pressure were recorded in EE-1 and the pressure was recorded in GT-2, which was shutin. The numerical fit to the GT-2 pressure response (10wer curve of Fig. 2) verifies the pressure dependence of $c / k$. The fits to the $E E-1$ pressure for the constant flow phases (Fig. 3) give the pressure dependence of Arkc. In Fig. 3, $P_{O}$ is the starting pressure for each constant flow phase. The important conclusions are as follows. Since the same pressure dependence of $k$ and $c$ fit both $A \sqrt{k c}$ and $c / k$ the assumption that the fracture area $(A)$ is independent of pressure at low pressures is justified. Since the pressure dependence of $k c$ and $c / k$ has been determined the pressure dependence of both $c$ and $k$ has been specified.

The second group of experiments (Figs. 4 through 6 ) is pressurizations of EE-1 or GT-2 with the other well shut-in. They are for constant injection flow rates and are presented in order of increasing flow period. The fits to the data were produced with the two-dimensional AYER with the goal of determining the time constant $\tau_{A}=A_{\mu c} / k$ for the conversion from one- to 


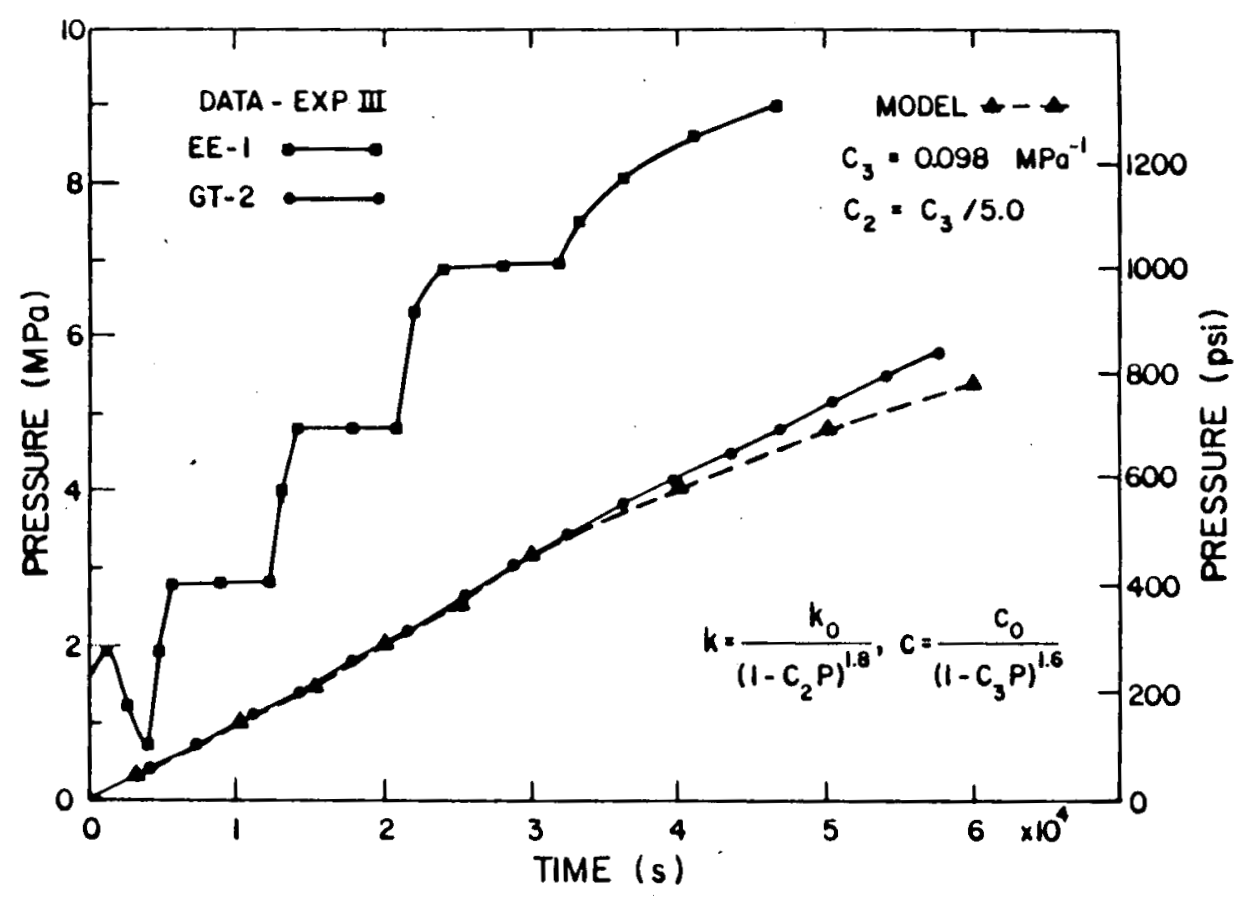

Fig. 2.

Pressure in EE-1 and GT-2 during experiment 111.

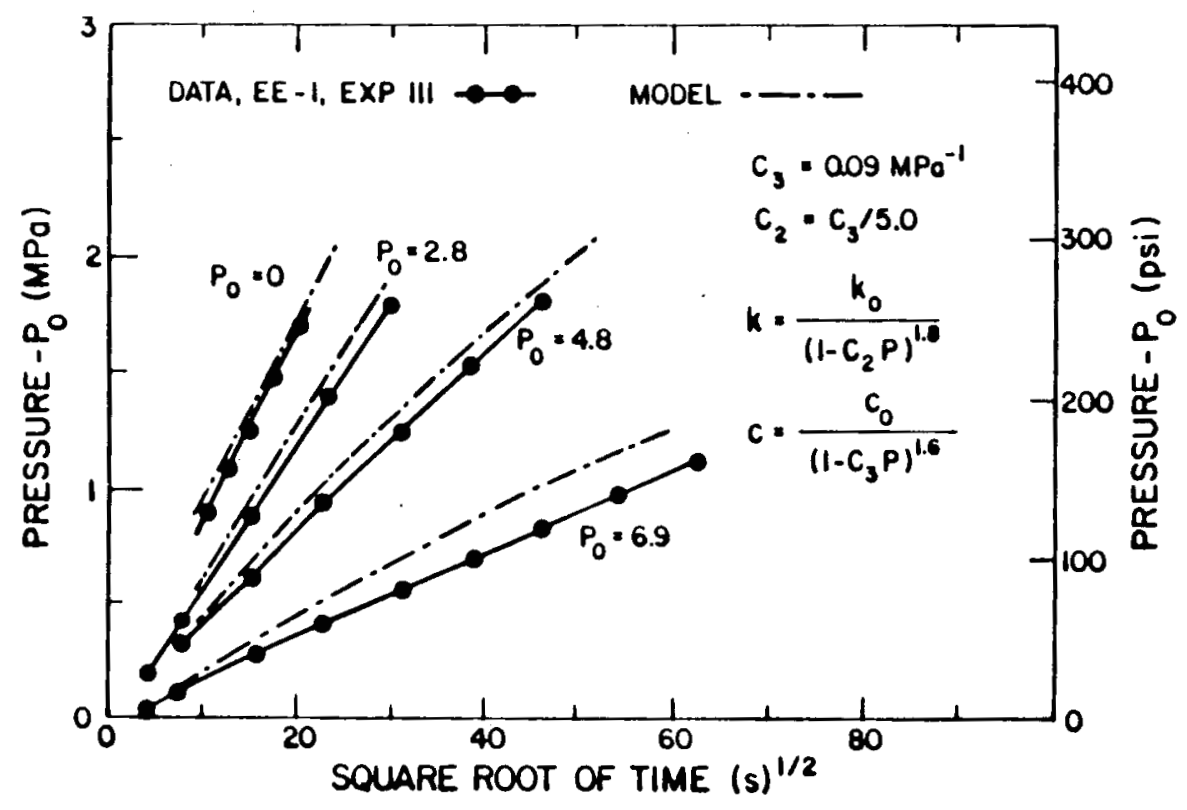

Fig. 3 .

Pressure in EE-1 during constant flow phases of experiment 111. 


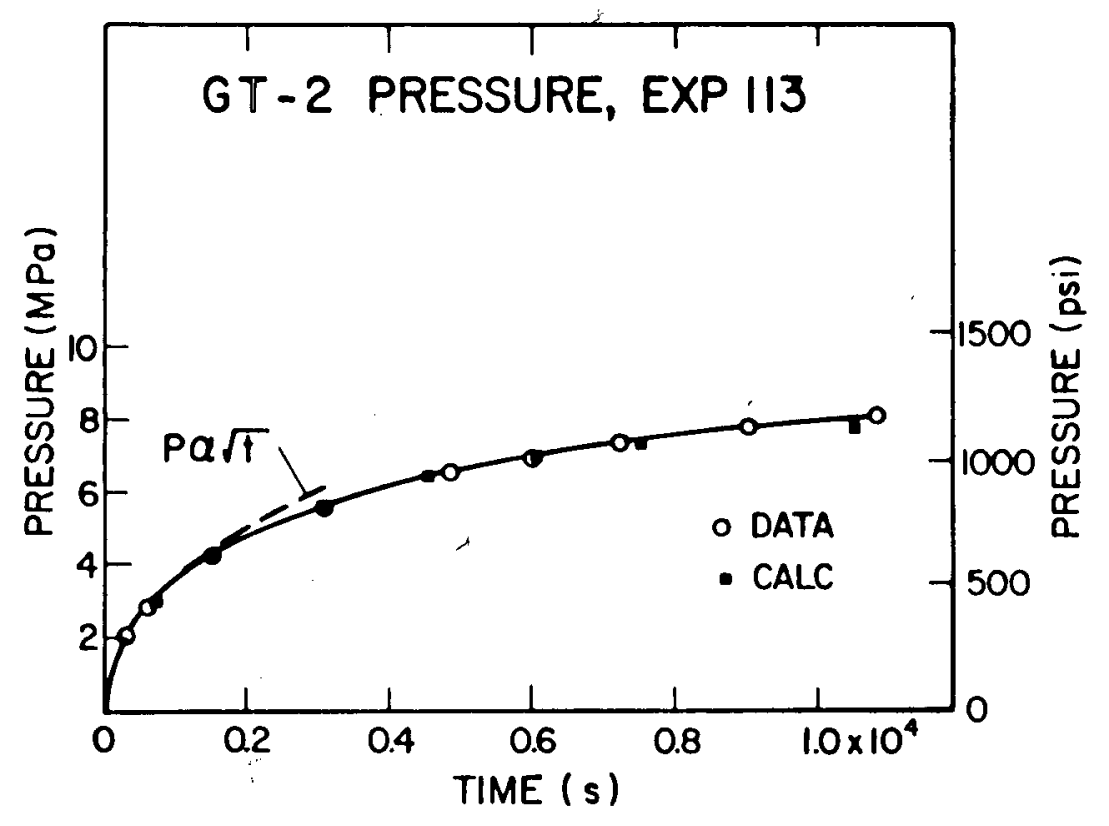

Fig. 4 .

Pressure in GT-2 for a constant injection flow rate during experiment 113 .

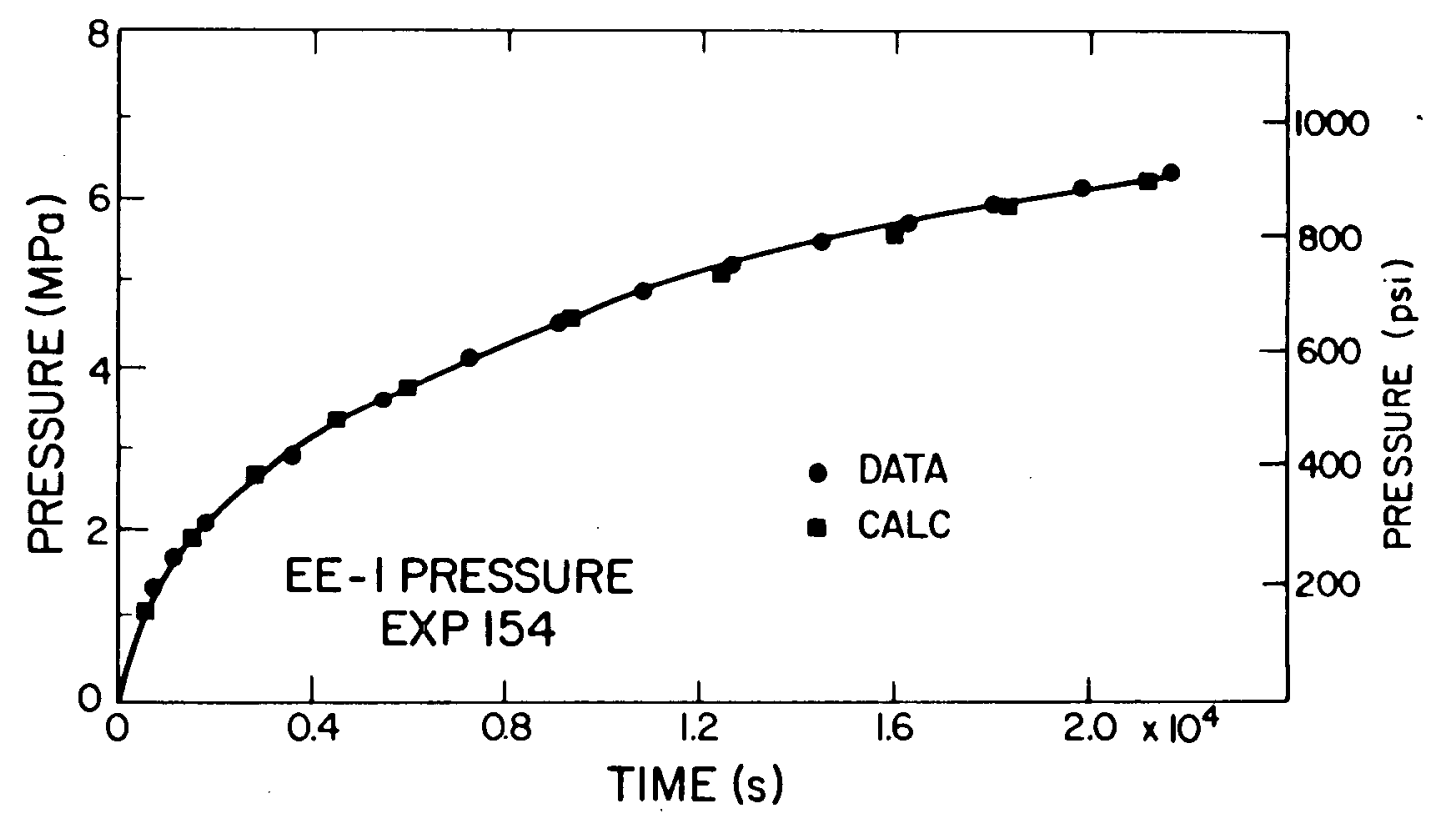

Fig. 5 .

Pressure in EE-1 for a constant injection flow rate during experiment 154 . 


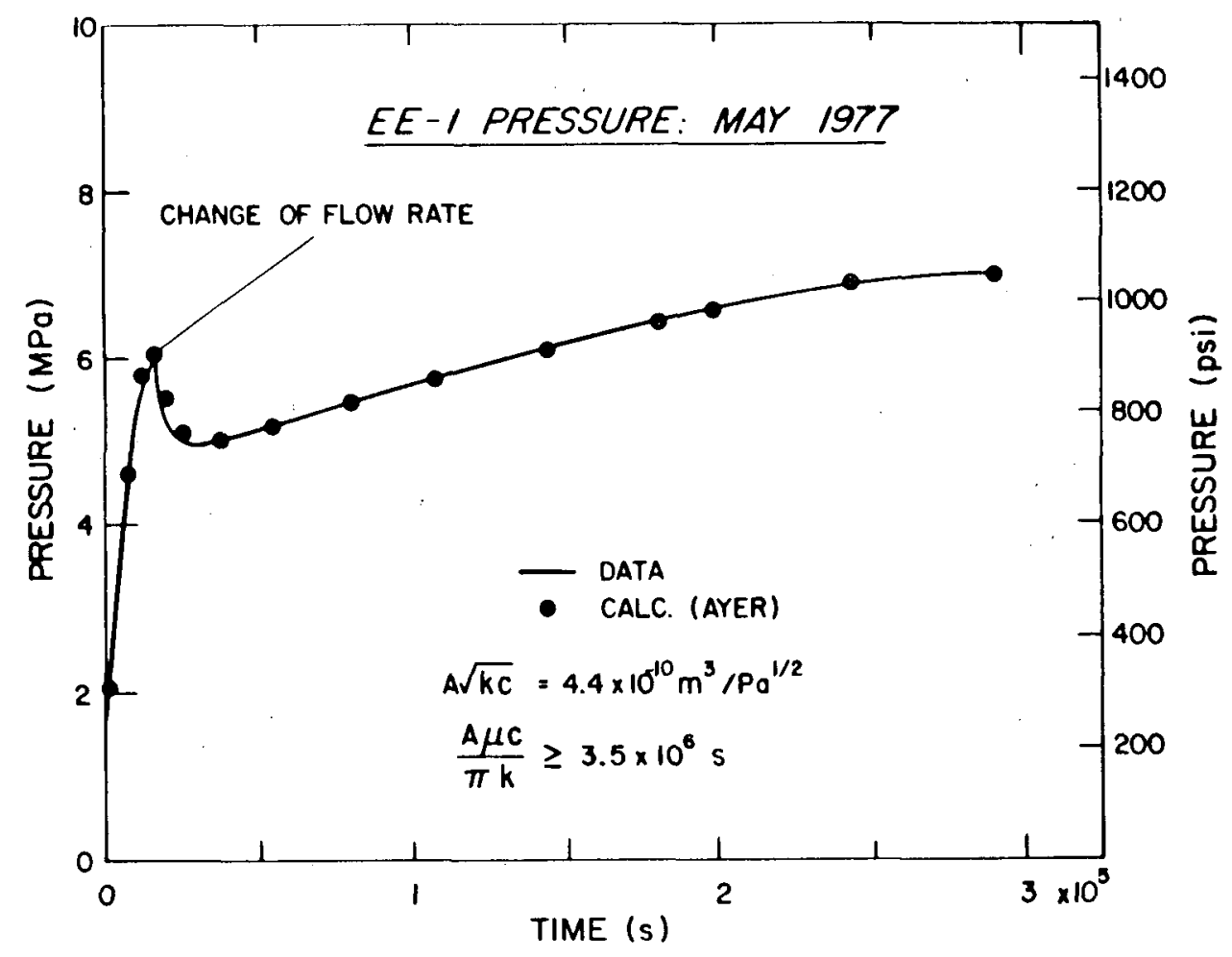

Fig. 6 .

Pressure in EE-1 for two constant flow phases of the May 1977 pump up.

multi-dimensional flow. There are three important aspects of these fits. Longer flows did not give any indication that the flow changed from oneto multi-dimensional flow and only a lower 1 imit to $\tau_{A}$ was established. Figure 4 shows that the same pressure dependence holds for the fractures connected to GT-2 and EE-1. The pressure dependence of the reservoir properties established by the short-term pumping holds for the longer flows, as long as the fracture pressure is smaller than the minimum earth stress.

The third group of experiments has flow periods longer than $\checkmark 100 \mathrm{~h}$. The long-term (75-day) closed-1oop continuous flow experiment, which is discussed in detail el'sewhere, ${ }^{14}$ added new information regarding the transient water storage by permeation flow. With the production hole (GT-2B) vented and flowing and the injection hole (EE-1) pressurized, the flow into permeation was from a series of fractures connected to the EE-1 wellbore. The flow rate and the integrated flow into permeation after the start-up transients are plotted in Figs. 7 and 8 . The rate has many transients due to operational changes (shutdowns for pump maintenance, etc.) but the theoretical calculations agree with an average loss rate. For the integrated flow the transients are not 


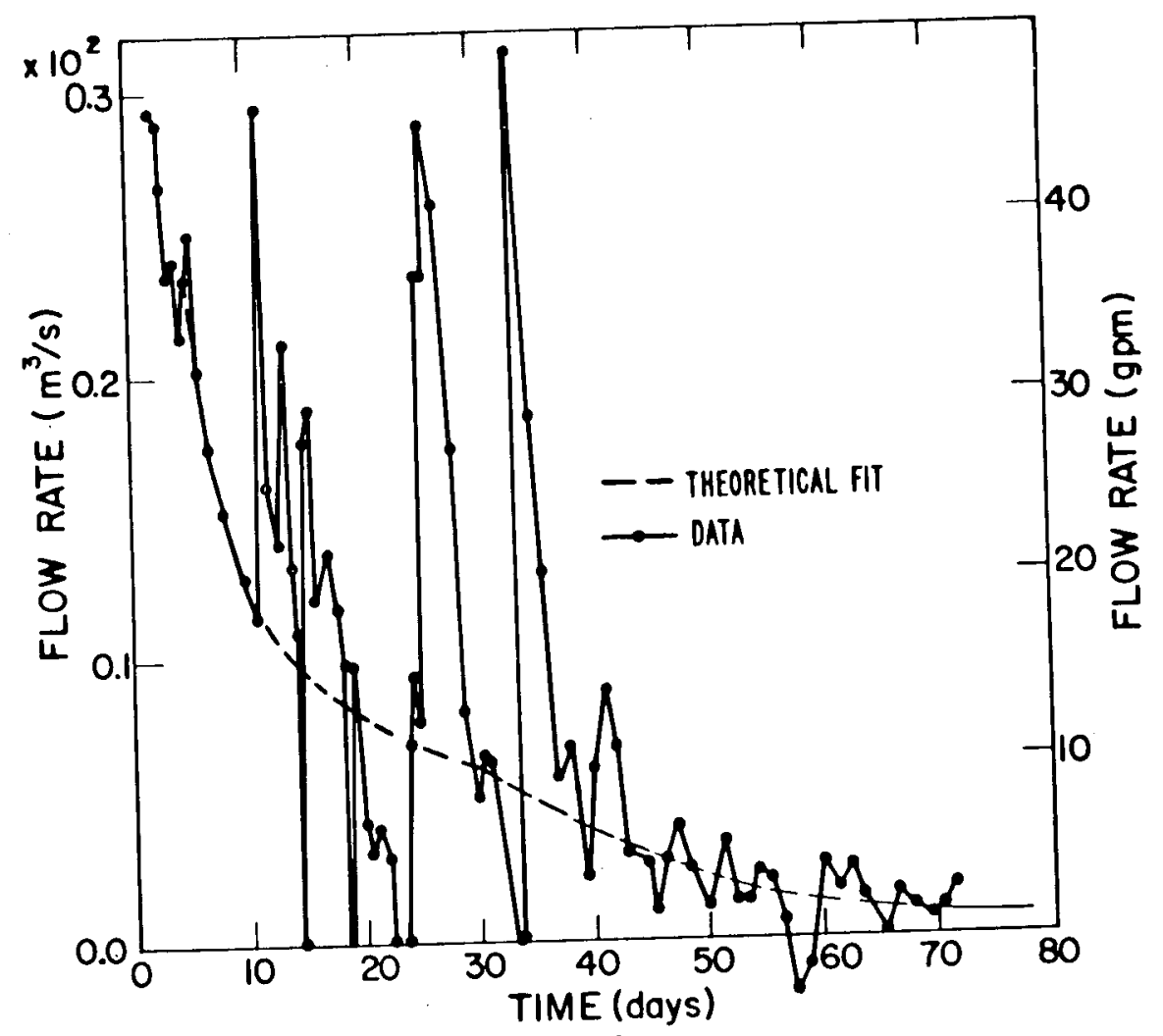

Fig. 7 .

Permeation flow rate (EE-1) injection rate minus GT-2 production rate during 75-day experiment of Phase I.

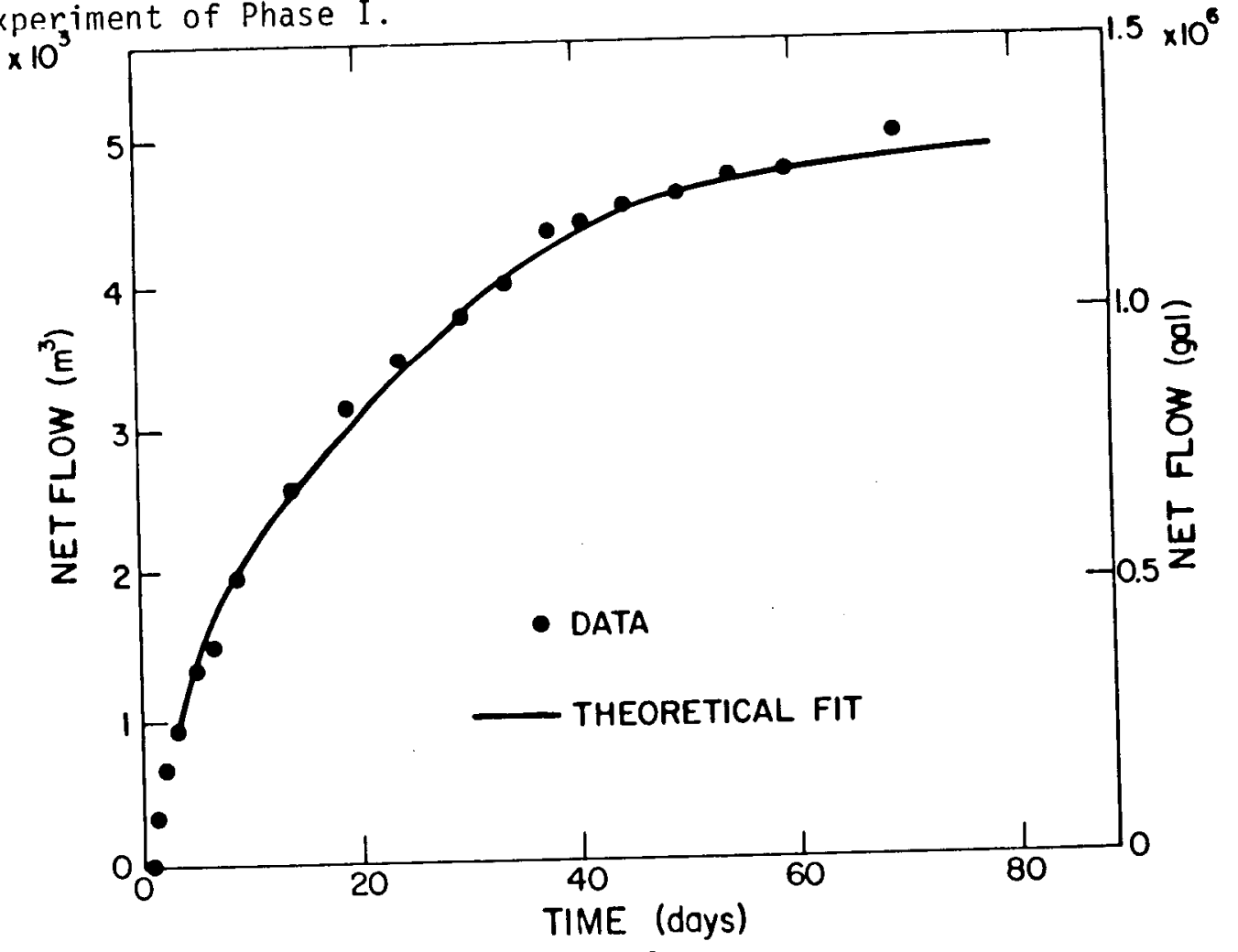

Fig. 8.

Integrated permeation flow during 75-day experiment of Phase I. 
obvious and the fit is good. The calculations were done with the two-dimensional AYER with the pressure-dependent properties. However, the time constant was so large that the flow was essentially one dimensional. That is, for flows as long as 75 days the data fits a one-dimensional model.

\section{B. Flow Dependence of Diffusion Parameters}

The search for a flow dependence of a at hydrostatic pressure in the Fenton $\mathrm{Hill}$ reservoir has been difficult because the systems undergo permanent changes during many experiments. In particular, $\alpha$ has exhibited permanent increases after some of the hydraulic fracturing experiments. However, if sequences of measurements can be found that contain smaller values of a obtained in later experiments, the effect may be flow dependent. Figure 9 is a plot of a versus flow rate $(\dot{Q})$ for three such sequences over the $E E-1$ pressurization history. Some trends are indicated; and, since, the specific flow rate is in the denominator of the permeability $\left(k \propto \dot{q}^{-1}\right)$ for turbulent flow, the decrease of a with $\dot{Q}$ is expected. This behavior with $\dot{Q}$ suggests that the appropriate flow law contains a term quadratic in the flux $\dot{q}$ rather than $a$ Darcy-type law, or

$$
\frac{1}{\mu} \nabla P=\bar{a} \dot{q}+\bar{b}^{2}
$$

Then

$$
k=\frac{k_{0}}{1+(\bar{b} / \bar{a}) \dot{q}}
$$

is the effective flow dependent permeability. We can check this approximately by comparing the data to

$$
\alpha=\frac{\alpha_{0}}{\sqrt{1+B \dot{Q}}} \text {, }
$$


where $\dot{Q}$ is the total flow rate. The solid lines on the graph of Fig. 9 show reasonable agreement with the data for a single value of the parameter $B$.

Since the trends in the data are consistent with the presence of a quadratic term in the flow law, it may be possible to obtain additional information on the flow regime and hence on the permeation characteristics of the fracture system.

The general characteristics of the impedance data for the three connections of EE-1 to the three branches of GT-2 are given in the graph of Fig. 10. On this plot a zero slope indicates no flow or pressure dependence. A positive slope indicates that the flow dependence dominates. A negative slope indicates either a pressure dependence because high pressures are associated with high flows, or it indicates that an intrinsic irreversible change is taking place in the system. Most of the measurements are not true steady state but are made after several hours of flow. In each case the production side (GT-2) was fully vented and hence near hydrostatic pressure. The EE-1 wellbore was pressurized between 4 to $10 \mathrm{MPa}(600$ to $1450 \mathrm{psi}$ ) above hydrostatic. The GT-2 connection showed little or no pressure or flow dependence. Any firm conclusion concerning the GT-2A connection was obscured by the small flow ranges examined and by uncertainties in the measurements. Any trends indicating a flow dependence for the GT-2B connection prior to the 75-day flow test are obscured by pressure dependences and intrinsic changes in the system (experiments 169 through 190). Experiment 184 measured the impedance at low flows and low pressures (<800 psi) after the system had been altered by the 75-day heat extraction experiment and a 28-day high back-pressure heat-extraction test. The impedance was found to have been reduced to permanently low values and despite the considerable scatter in the flow rate data as measured by a turbine meter, a real dependence on the GT-2B flow is indicated.

If both EE-1 and GT-2 are pressurized, the pressure dependence dominates. The few measurements of this type are covered in detail by Brown. 15 They are used later to obtain fracture compressibilities.

We first consider the case of the inflation of a single (or few) discrete fractures. In this case it can be shown that the Reynolds number is in the transition region between laminar and turbulent flow for the flow rates normally used and for the expected fracture dimensions. If the surfaces of the fracture are rough, turbulent flow is induced at much lower Re. Figure 11 illustrates the approximate dividing line (dashed curve) between laminar and 


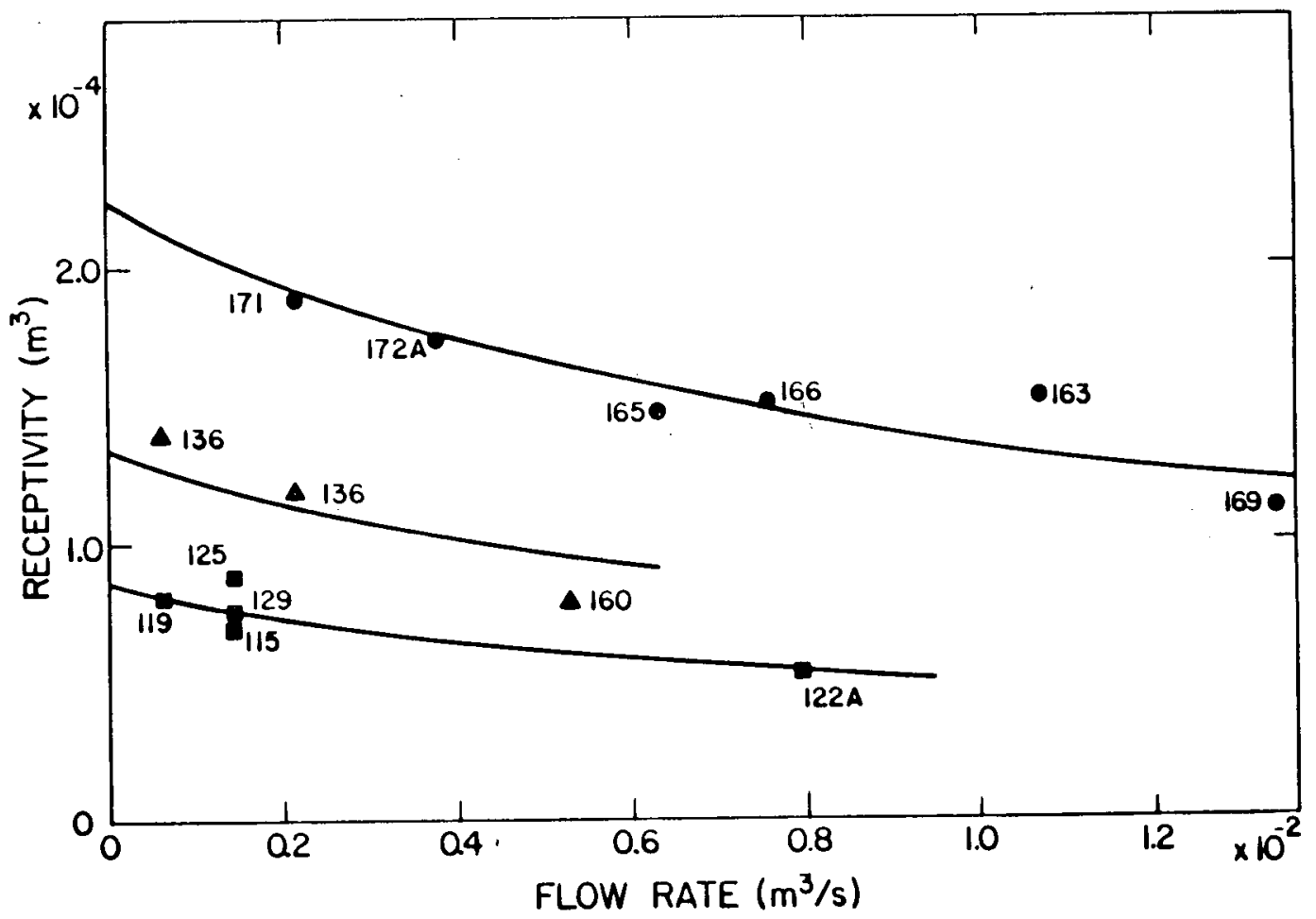

Fig. 9.

Receptivity $\left(\alpha=A \sqrt{k C / C_{R}}\right)$ versus flow rate for $E E-1$.

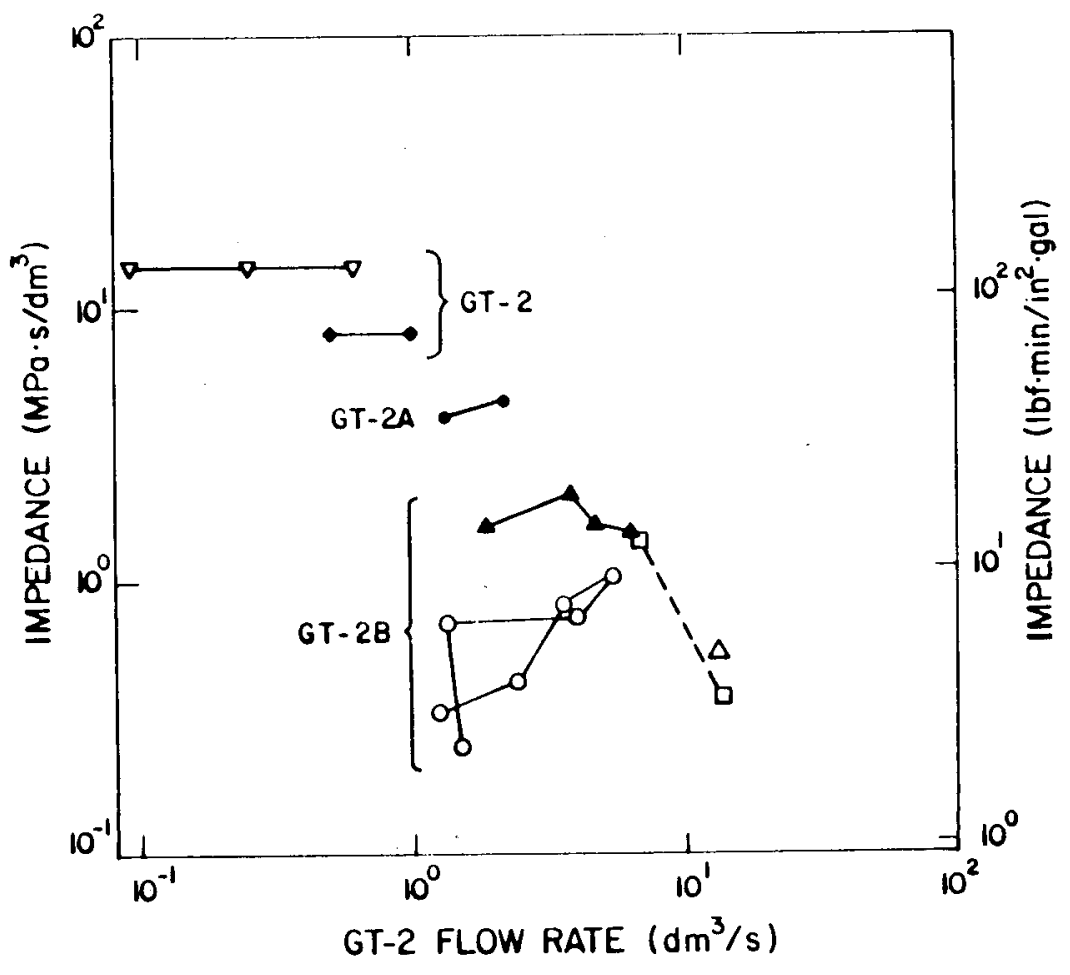

Fig. 10 .

Flow impedance for the various EE-1 to GT-2 connections. 


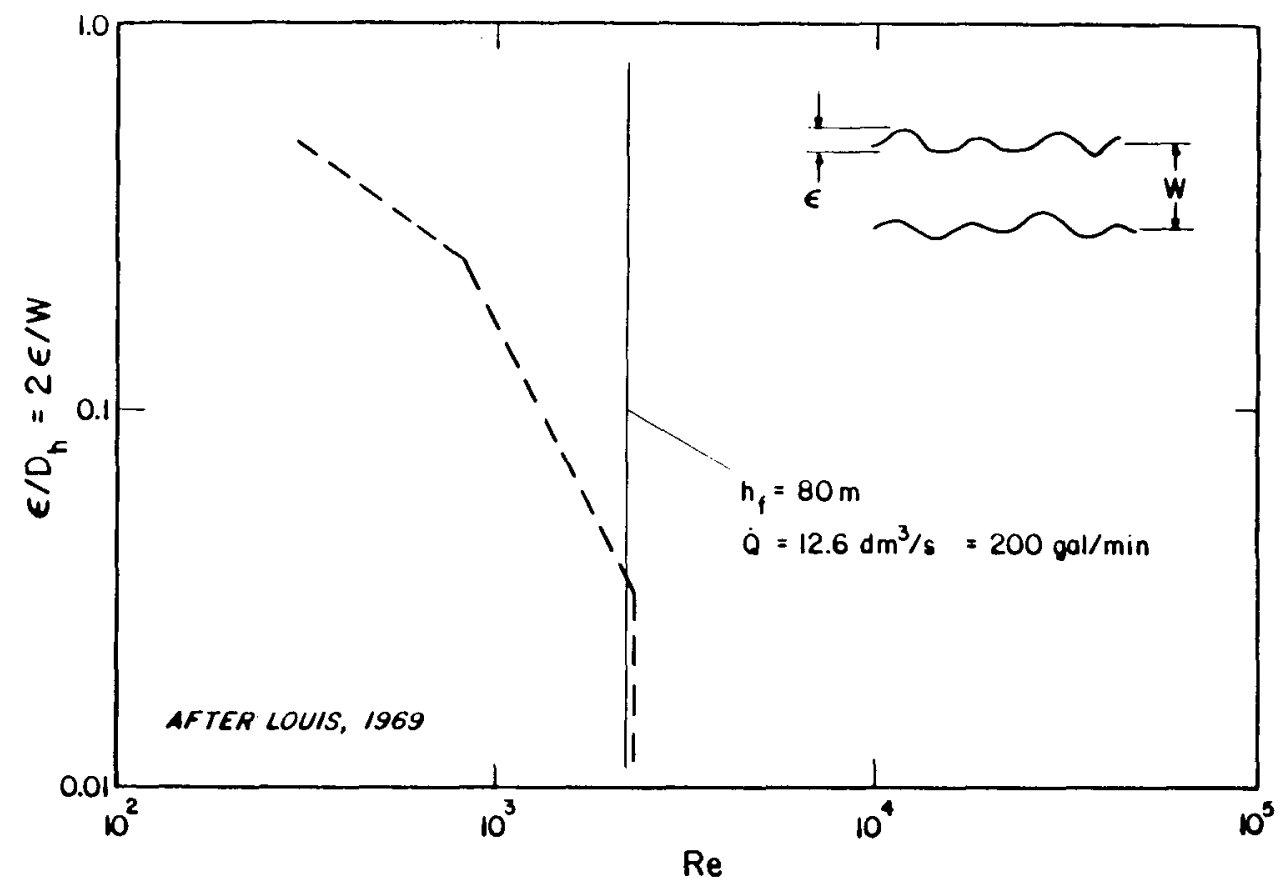

Fig. 11 .

Transition region for laminar-to-turbulent flow. ${ }^{16}$

turbulent flow as determined by Reynolds number ( $R e$ ) and relative roughness, $2 \varepsilon / W^{16}$ Here $W$ is the fracture thickness and $\varepsilon$ is the roughness. The solid vertical line is Re for a flow of $1.26 \times 10^{-2} \mathrm{~m}^{3} / \mathrm{s}(200 \mathrm{gpm})$ into a fracture of $80 \mathrm{~m}(262 \mathrm{ft})$ in height. In the Fenton $\mathrm{Hill}$ inflation tests the total input flow has been varied from 0.21 to over $1.26 \times 10^{-2} \mathrm{~m}^{3} / \mathrm{s}$. However, the specific flow rate in any part of the fracture is unknown because the fracture geometry, as well as the exact condition of roughness, is unknown. For these reasons the distribution of laminar, induced turbulent, or turbulent flow throughout the fracture cannot be specified. Any ratio of linear and quadratic terms in Eq. (11) is possible and relates only to average conditions.

The usual interpretation of the early time pressure response is that it is due to permeation into the porous rock surrounding a large fracture with zero internal impedance or infinite conductivity. However, the flow dependence of the data suggest that the conditions be examined for which Darcy's law no longer holds. Furthermore, it has been suspected that any permeation flow would be dominated by larger scale joints rather than the microstructure of grain boundaries. ${ }^{4}$ If this is the case, the extremely low Reynolds numbers associated with the flow in the microstructure would not be appropriate and non-Darcy effects may appear. In addition, flow in permeable (packed) beds 


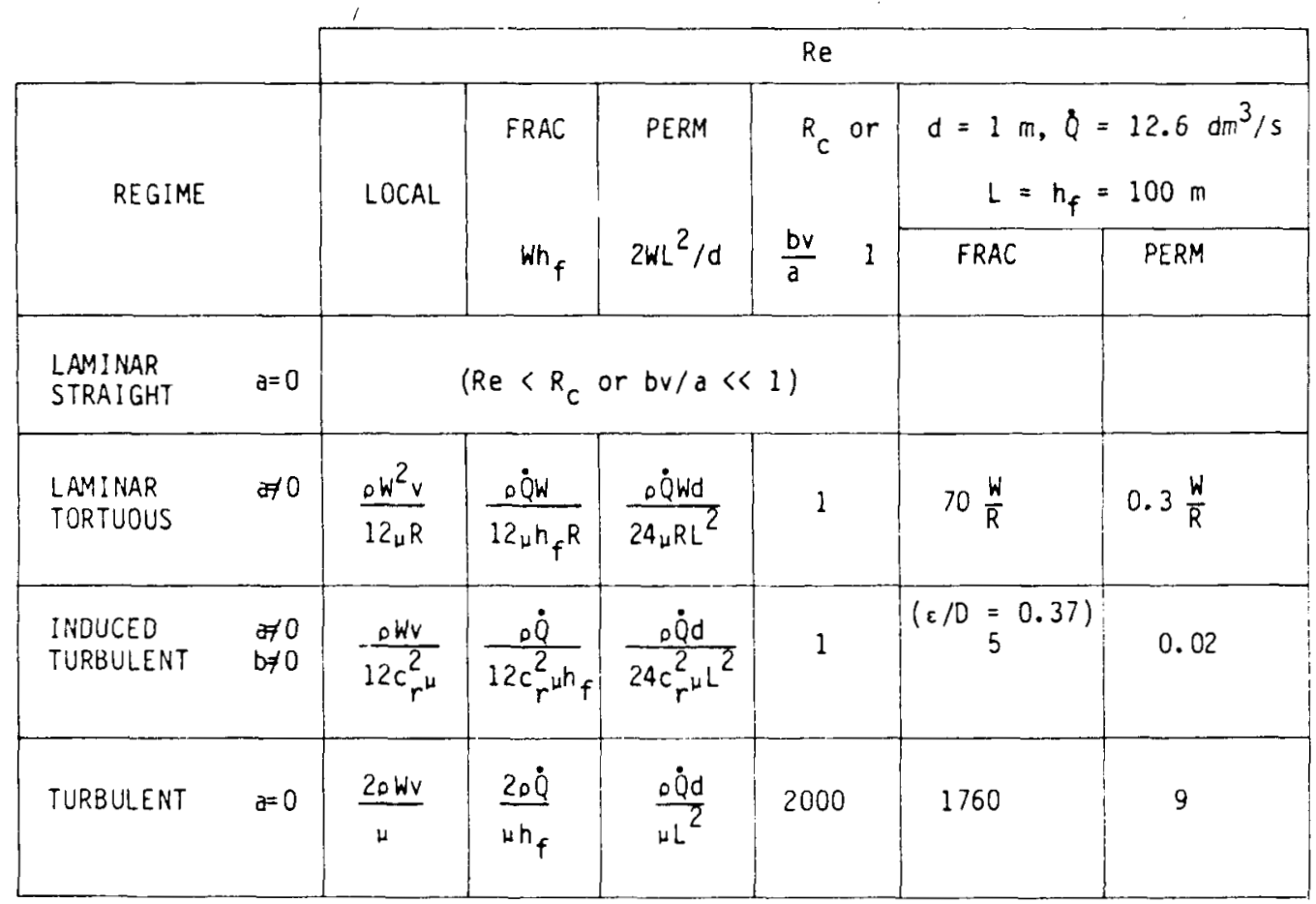

Fig. 12 .

Table of parameters determining flow regimes.

exhibits a gradual transition from linear to quadratic flow at low Reynolds numbers. The various reasons for this are discussed by many authors. ${ }^{16-18}$ The table of Fig. 12 summarizes the situation for flow into a fracture or matrix permeation. The size parameters are defined in the nomenclature. Considerable uncertainty exists in the literature as to which effects are most important in the classification of the flow regimes. Here the general discussion of the previously cited references has been followed. With a flow law of the type given by Eq. (11) but in terms of the local fluid velocity $v$,

$$
\nabla P=a v+b v^{2},
$$

four flow regimes can be recognized. In the laminar straight regime at low Re no quadratic term exists. For laminar tortuous the quadratic terms arise because the flow is constantly changing directions. Here the onset of quadratic flow is gradual with the critical Reynolds (Re) number determined when the ratio of the quadratic-to-linear term (bv/a) approaches one. For turbulence 
induced by wall roughness the onset is al so gradual and the critical Reynolds number is again specified when the ratio of the quadratic to the linear term approaches one. In the turbulent regime the Reynolds number is the familiar one with a critical value of $\sim 2000$. In Fig. 12 the Re are listed in terms of three sets of parameters. The first is the local parameters. The second is for flow in a single fracture of cross-sectional area $W \times h_{f}$. The third is for permeation over an area $\left(L^{2}\right)$ with permeating cracks of width $W$ and spacing d. The next column is the critical values of each. The last two columns are the values of $R c$ resulting from the possible set of $\dot{Q}=200 \mathrm{gpm}, d=1.0 \mathrm{~m}$, and $L=h_{f}=100$. It is obvious that because of the wide possible ranges of $Q, d, L, h_{f}, W / R$ and $\varepsilon / D_{h}$ that the quadratic term can contribute significantly to either or both fracture flow or matrix permeation. The situation is even less clear if the permeation is occurring mainly in high-impedance extensions of the main fracture.

\section{FRACTURE COMPRESSIBILITY}

Possibly in situ measured fracture compressibilities could help distinguish between permeation and fracture flow. However, if the scale (crack spacing) of the permeation is large compared to the microstructure this is probably not the case. An internally consistent interpretation of the observed in situ pore compressibility and related permeability in terms of permeating cracks with a spacing of the order of $1 \mathrm{~m}$ was given in an earlier report. 4 Here we interpret this in terms of flow in a single fracture and examine the evidence that many large fractures have approximately the same compressibility and that it is determined largely by the effective confining stress.

We are interested in the fracture compressibility,

$$
c_{f}=\frac{1}{V_{f}} \frac{d V_{f}}{d P}
$$

for a fracture of volume $V_{f}$ and with internal pressure $P$. For a constant fracture surface area, 


$$
c_{f}=\frac{1}{W} \frac{d W}{d P}
$$

where $W$ is the fracture width or aperture. As shown by Witherspoon et al. (Ref. 9), and the other cases that follow, fracture apertures obey the law

$$
W \propto \frac{1}{\left[1+\left(\sigma / M_{0}\right)\right]^{n}}, \sigma=P_{c}-P,
$$

where $P_{C}$ is the confining stress, $P$ is the fluid pressure, and $M_{0}$ is a fracture modulus. Then,

$$
W=\frac{W_{0}}{(1-C P)^{n}}, C=\frac{1}{M_{0}+P_{C}} \text {, }
$$

and

$$
c_{f}=\frac{n C}{(1-C P)}
$$

And, at $P=0$

$$
c_{f}=c_{f o}=n C
$$

Four estimates of $c_{f o}=n C$ for large fractures follow.

The low flow part of the diffusion parameter for Fenton $\mathrm{Hill}$ when interpreted as flow in a single fracture fits

$$
\alpha=A_{c} \sqrt{k_{f} c_{f}}=h_{f} W\left(\frac{W^{2}}{12} c_{f}\right)^{1 / 2} \times \frac{1}{(1-C P)^{n}} .
$$

Where, $n \backsim 1$ and $c=0.1 \mathrm{MPa}^{-1}$. Then from Eqs. $(18),(19)$, and $(21), \mathrm{n}=$ $(4 n+1) / 2=1$ gives $n=0.25$ and $c_{f o}=2.5 \times 10^{-2} \mathrm{MPa}^{-1}$.

The fracture compressibility also affects the pressure-dependent flow through impedances. For experiment 161 the connection between EE-1 and GT-2A had an impedance given by 


$$
I=I_{0}\left(1.0-\frac{P}{P_{c}}\right)^{n}, I_{0}=5.5 \frac{\mathrm{MPa}^{S}}{\mathrm{dm}^{3}}=50 \mathrm{psi}-\mathrm{min} / \mathrm{gal} \text {. }
$$

For experiment 186 for $E E-1$ and GT-2B

$$
I=I_{0}\left(1.0-\frac{P}{P_{c}}\right)^{n}, I_{0}=0.55 \frac{\mathrm{MPa}^{s}}{\mathrm{dm}^{3}}=5 \mathrm{psi}-\mathrm{min} / \mathrm{gal} \text {. }
$$

In both cases the EE-1 pressure was constant, $P$ is the GT-2 back pressure, $n=$ 1.0 , and $P_{C}=10.4 \mathrm{MPa}$. For most flow regimes $I \propto W^{-3}$; then

$$
W=\frac{W_{0}}{(1-P / 10.4)^{1 / 3}},
$$

and $c_{\text {fo }}=3.2 \times 10^{-2} \mathrm{MPa}$.

Similar values of compressibility can be deduced from measurements made on single fractures in large $(n 1 \mathrm{~m})$ blocks of granite. Witherspoon, 10 finds the crack displacement in Sierra White granite for saw cut fractures to be

$$
W \propto \frac{1}{\left[1+\left(\sigma / M_{0}\right)\right]^{0.48}},
$$

where $M_{0}=0.305 \mathrm{MPa}$.

Assuming that the effective stress $\sigma=P_{C}-P$ appropriate, we have

$$
W=\frac{W_{0}}{\left[1-\left(P / M_{0}+P_{C}\right)\right]^{0.48}}
$$

For the confining stress of $10 \mathrm{MPa}$ (approximately that of the Fenton Hill reservoir), $c_{\text {fo }}=4.6 \times 10^{-2} \mathrm{MPa}^{-1}$. 
Investigators at the Lamont Dougherty Laboratories ${ }^{10}$ have measured the product of fracture permeability and cross-sectional area for tension fractures in Barre granite. They find

$$
k_{f} A_{c} \propto \frac{1}{\left[1-\left(P / P_{c}\right)\right]^{1.1}}
$$

or

$$
W=\frac{W_{0}}{\left[1-\left(P / P_{C}\right)\right]^{0.36}} \text {. }
$$

Then $c_{\text {fo }}=3.6 \times 10^{-2} \mathrm{MPa}^{-1}$.

The exponent $n$ seems to have a small range and $M_{0}$ is generally small for large fractures. Hence the compressibility at $P=O$ is determined mainly by the confining stress. The pressure dependences of receptivity $A_{c} \sqrt{k_{f} c_{f}}$ and impedance I, as measured at Fenton Hill, give values of the exponent $n$ that are close to those measured in the laboratory.

\section{APPROXIMATE RESERVOIR SIZE CALCULATIONS}

We next review the parameters that depend on the reservoir dimensions and then present two graphical summaries of the limits on these parameters for early and late time flows.

\section{A. Fracture Dimensions from Impedance Measurements}

If the inflation process consists of flow in discrete fractures, it is reasonable to assume that they have roughily the same characteristics as the through-flow paths. In fact, they could be wholly or partly the same. As indicated in the last section and earlier reports, 4,15 the impedances have a pressure dependence. The degree of this dependence depends on the connection in question. The impedance of the connection between EE-1 and GT-2B in particular depends strongly on the GT-2B pressure. This connection has exhibited a flow dependence that has not been obvious in the other connections. Since 
considerable data exist for this connection, we will use it to calculate a range of possible fracture dimensions.

For the approximate calculation of fracture dimensions we will pick nominal values of impedance and flow rate for the case of low GT-2B pressure. For a low EE-1 pressure (experiment 184) the impedance was $0.55 \mathrm{MPa}-\mathrm{s} / \mathrm{dm}^{3}$ (5 psi/gpm) at $3.15 \mathrm{dm}_{3} / \mathrm{s}$ (50 gpm); for a high EE-1 pressure (experiment 190) the impedance was $0.55 \mathrm{MPa}-\mathrm{s} / \mathrm{dm}^{3}(5 \mathrm{psi} / \mathrm{gpm})$ at $12.6 \mathrm{dm}^{3} / \mathrm{s}(200 \mathrm{gpm})$. The linear dependence of impedance on flow rate in experiment 184 indicates that turbulent or rough-wall theory is appropriate. Large relative roughness values $\left(\varepsilon / D_{h}=1 / 3\right.$ and 1$)$ are used in this calculation. The well-known theory of Blasius ${ }^{16}$ for turbulent flow in a smooth wall conduit gives,

$$
I=0.004 \frac{\mu L}{W^{3}}(R e)^{3 / 4} \text {, }
$$

with

$$
\operatorname{Re}=\frac{2 \rho_{w} \dot{Q}}{\mu k_{f}} \text {. }
$$

From the theory of flow past rough walls by Nikuradse ${ }^{8}$ the impedance is

$$
I=\frac{\dot{Q}_{\rho_{w}}}{16\left(\log \frac{3.7}{\varepsilon / D_{h}}\right)^{2} h_{f}{ }^{2} w^{3}} .
$$

Later in this report the fracture dimensions given by these formulas are compared graphically with those obtained from the considerations presented in earlier sections.

\section{B. The Zero Impedance Volume at Hydrostatic Pressure} When the fracture system connected to the EE-1 injection wellbore is pressurized at a constant flow rate, the pressure begins to rise almost immediately as the square root of time. For values of $\alpha_{f}=A_{c} \sqrt{k_{f} c_{f}} / c_{0}$ greater than $100 \mathrm{~cm}^{3}$ any linear rise due to wellbore or fracture compressibility is barely 
detectable. This can be interpreted to mean that the change of volume of the fracture that is directly connected (by zero impedance) to the wellbore is small compared to the change of volume of the water in the wellbore,

$$
\begin{aligned}
& \Delta V_{f} \leq \Delta V_{w}, \\
& c_{f} V_{f} \leq c_{w} V_{w},
\end{aligned}
$$

and

$$
v_{f} \leq\left(c_{w} / c_{f}\right) v_{w}
$$

Using the values of $V_{w}=79 \mathrm{~m}^{3}$ for $E E-1, C_{w}=50 \times 10^{-5} \mathrm{MPa}^{-1}$, and the value of $c_{f} 3.0 \times 10^{-2} \mathrm{MPa}$ obtained earlier, we have

$$
v_{f} \leq \frac{5.0 \times 10^{-4}}{3 \times 10^{-2}} 79 \mathrm{~m}^{3}
$$

or

$$
v_{f} \leq 1.3 \mathrm{~m}^{3}
$$

However, the fracture width for this zero impedance volume must be large, $W>2 \times 10^{-3} \mathrm{~m}$, or the permeability will contribute directly to $A_{c} \sqrt{k_{f} c_{f}}$, which is the condition for nonzero impedance. Then

$$
v_{f}=W A_{f} \leq 1.3 \mathrm{~m}^{3},
$$

and

$$
W>2 \times 10^{-3} \mathrm{~m}
$$


imply that

$$
A_{f}<600 m^{2}
$$

Or in equivalent fracture radius

$$
r_{f}<14 m \quad .
$$

The significance of this small zero impedance volume and area will be discussed later.

C. Fracture Dimensions from the Diffusion Parameter

As described earlier, the diffusion parameter $\alpha_{f}=A \sqrt{k c}$ has both a flow dependent part and a finite limit for zero flow (Fig. 9). This low flow value of $\alpha_{f}$ can be interpreted as the laminar flow property of a discrete fracture. In this case the area term $A$ in $\alpha_{f}$ becomes the cross-section area of the fracture perpendicular to the flow,

$$
A_{c}=h_{f} w,
$$

where $h_{f}$ is the large fracture dimension perpendicular to the flow. The appropriate permeability is the fracture permeability for Darcy flow,

$$
k=\frac{W^{2}}{12}
$$

and the compressibility is the fracture compressibility given by Eqs. (15) and $(16)$,

$$
c_{f}=\frac{1}{V_{f}} \frac{d V_{f}}{d P} .
$$

Then

$$
\alpha_{f}=A_{c} \sqrt{k_{f} c_{f}}=h_{f} w \sqrt{\frac{W^{2}}{12} c_{f}},
$$


and

$$
W=\left(\frac{12}{c_{f}}\right)^{1 / 4}\left(\frac{\alpha_{f}}{h_{f}}\right)^{1 / 2} .
$$

This relationship will be used to calculate the possible ranges of $h_{f}$, $W$, and $c_{f}$ at hydrostatic pressure.

The use of the flow dependent part of the permeability [the constant B in Eq. (13)] requires an assumption regarding the physical origin of the quadratic term in the flow law (Eq. 11). Also the distribution of flow must be known since different flow regimes can occur at different positions in the fractures. The simultaneous occurrence of linear and quadratic terms of the same size in the flow law can result from a laminar tortuous regime or an induced turbulent regime. Also, the occurrence of turbulent flow and laminar flow in different parts of the fractures or any combination of these effects can result in the observed flow dependence of the receptivity.

Despite all these difficulties we will do an order-of-magnitude estimate of the fracture size. From the fit to the data of Fig. 9 we saw that the linear and quadratic terms were equal at $\dot{Q}=100 \mathrm{gpm}=6.309 \mathrm{dm}^{3} / \mathrm{s}$. From the table of Fig. 12 for flow in a fracture of cross-sectional area $W \times h_{f}$ and roughness coefficient $c=4 \log \left(3.7 D_{h} / \varepsilon\right)$ we have,

$$
\frac{\rho_{w} \dot{Q}}{12 c_{r^{\mu} h_{f}}^{2}}=1.0 .
$$

Or, for a nominal $\varepsilon / D_{h}=0.37$ and $\dot{Q}=6.3 \mathrm{dm}^{3} / \mathrm{s}(100 \mathrm{gpm}), \mathrm{h}_{\mathrm{f}}=230 \mathrm{~m}$. This is consistent with the other estimates. For the laminar tortuous regime

$$
h_{f}=\frac{\rho_{W} \dot{Q}}{12 \mu} \bar{R} .
$$

Or at $\dot{Q}=6.3 \mathrm{dm}^{3} / \mathrm{s}(100 \mathrm{gpm})$

$$
W=3.75 \times 10^{-3} W / R \text {, }
$$


and a relatively large local radius of curvature will give a significant contribution to the quadratic term.

D. Fracture Dimensions from Dye Studies and Temperature Data

The flow volume and heat-exchange areas have been measured for the case of EE-1 pressurized to $s 1400 \mathrm{psi}$ and GT-2B at zero. The dimension under these conditions can be expected to be larger than those at hydrostatic pressure.

At the end of the 75-day experiment the mean flow volume was $\backsim 56 \mathrm{~m}^{3}$ as measured by the dye tracers. ${ }^{19}$ In terms of average dimensions

$$
V_{f}=W A_{f}=56 \mathrm{~m}^{3}
$$

For a separation of inlet and outlet of $s 100 \mathrm{~m}$,

$$
W=\frac{0.56}{h_{f}}
$$

The heat-exchange area measured at the same time was $A_{f} \backsim 8 \times 10^{-3} \mathrm{~m}^{3}$. If this area is approximately that appearing in Eq. (49), then $W \sim 7 \times 10^{-3} \mathrm{~m}$.

\section{GRAPHICAL SUMMARIES}

All of the flow characteristics discussed in the previous sections can come from fractures of roughly the same average dimensions, $w$ and $h_{f}$. This is due, at least in part, to the number of parameters that have not yet been determined. In particular, those parameters that determine the distribution of the possible flow regimes throughout the fracture are uncertain. However, the hypothesis outlined in the introduction does not lead to any immediate inconsistencies. Two important points must be kept in mind. (1) The assumption has been made that the flow into what may be a complex fracture system can be characterized by the three average parameters $c_{f}$, $w$, and $h_{f}$. That is, $W$ and $c_{f}$ may be averages over several fractures and $h_{f}$ may be the combined length of several fractures. (2) None of the complications arising from the possibility of radial flow have been introduced. For instance, if the impedances are concentrated near the wellbores by convergent flow, more free parameters can be introduced and the situation becomes even less certain. 
In Fig. 13 the relation of $w$ to $h_{f}$ for an average value of $c_{f}=3.0 x$ $10^{-2} \mathrm{MPa}^{-1}$ as estimated for the Fenton $\mathrm{Hill}$ fractures. The solid 1 ines labeled with the values of $\alpha_{f}$ are from Eq. (45). The range of $\alpha_{f}$ is from the zero flow limit observed in Fig. 9 so the laminar theory is appropriate. The dashed lines indicate a possible range of $W$ and $h_{f}$ as calculated with Eq. (29) and (31) and impedance values obtained in experiments 184 and 190. A value of $\varepsilon / D_{h}=1$ was used for experiment 184 and fully turbulent conditions for experiment 190. ' It should be kept in mind that the impedance measurements have been made with one side (EE-1) of the system pressurized and it would be expected that the resulting values of $\Delta$ would be somewhat larger than those obtained from $\alpha_{f}$ measurements. The lines labeled. with values of $v_{f}$ are for the fracture volume estimates. The curve $v_{0}=1 \mathrm{~m}^{3}$ set limits on the zero impedance volume as determined earlier. The dimension of this volume must fall below this curve but well above the two $\alpha_{f}$ curves. The $v_{f}=56 \mathrm{~m}^{3}$ is the fracture volume from dye tracer studies at the end of the 75-day experiment. 18 The vertical line labeled $\sqrt{A_{T}}$ is the square root of the heat-excharige area of the 75-day experiment. The vertical line labeled $B \dot{Q}=1$ is the dimension transverse to the flow as obtained from the ratio of the linear-toquadratic terms in $\alpha_{f}$ for a rough fracture, $\varepsilon / D_{h}=0.37$.

Approximate limits can al so be obtained for those parameters that determine the long-term water losses of the system. By assuming that the long-term linear water loss is a formation flow and by assuming a canonical value of pore compressibility as obtained in the laboratory $\left(\mathrm{c}=4.0 \times 10^{-5} \mathrm{MPa}^{-1}\right)$, an upper limit on the permeating area and on the effective value of permeability can be determined. Figure 14 is a plot of effective permeability confining the system versus the square root of the permeating area. Each straight line represents a limit set by some measured parameter, the allowable portion of the graph is indicated by the direction of the arrow. The parameters and limits annotated on the figure are

\footnotetext{
$\tau_{A}:$ limits set by one-dimensional nature the flow

$\dot{Q}$ : limit set by small value of long-term water loss rate

$\sqrt{A_{T}}$ : limit set by assuming that the permeating area is larger than the heat exchange area

$k$ : limit set by smallest laboratory permeability
} 
$A \sqrt{k C}$ : limit set by assuming that this parameter is determined only by the small-scale porosity

$v_{v}$ : limit set by approximate venting volumes.

VII. SUMMARY

The general characteristics of the pressure transient testing data for the first Fenton Hill HDR reservoir have been summarized. The data have been analyzed in terms of a diffusion equation for pore pressure with pressuredependent permeability and compressibility.

The diffusion parameters governing injection $(\alpha=A \sqrt{\mathrm{kC}})$ and circulation $(I=P / \dot{Q})$ were determined by fitting model calculations to the data. This empirically determined pressure dependence for the fracture properties was shown to be similar to those obtained by other investigators in laboratory experiments on large fractures.

A flow dependence of the receptivity $\alpha$ was observed in the data for injection tests spanning several years. This receptivity was interpreted in terms of a permeability having a flow-dependent and a constant (laminar) part. It was shown that this behavior could result from either fracture flow or formation (matrix) flow if the formation flow is dominated by cracks and joints rather than the microporosity.

of the three flow-through connections the impedance of the final one between EE-1 and GT-2B was found to be flow dependent as well as pressure dependent. Rough wall and turbulent flow theories were used to show that the transition to nonlaminar flow occurred at reasonable specific flow rates. Finally the parameters obtained from the flow data were combined with those from dye tracer, thermal drawdown, and laboratory permeability data to obtain approximate fracture dimensions and limits on permeating area and effective confining permeability. To obtain these estimates it was assumed that the early-time injection data were dominated by linear fracture flow with pressure- and flow-dependent properties and that the long-term linear water loss is associated with a large permeating area. These results are summarized in Figs. 13 and 14, and show that an internally consistent picture can be developed in terms of average fracture dimensions. 


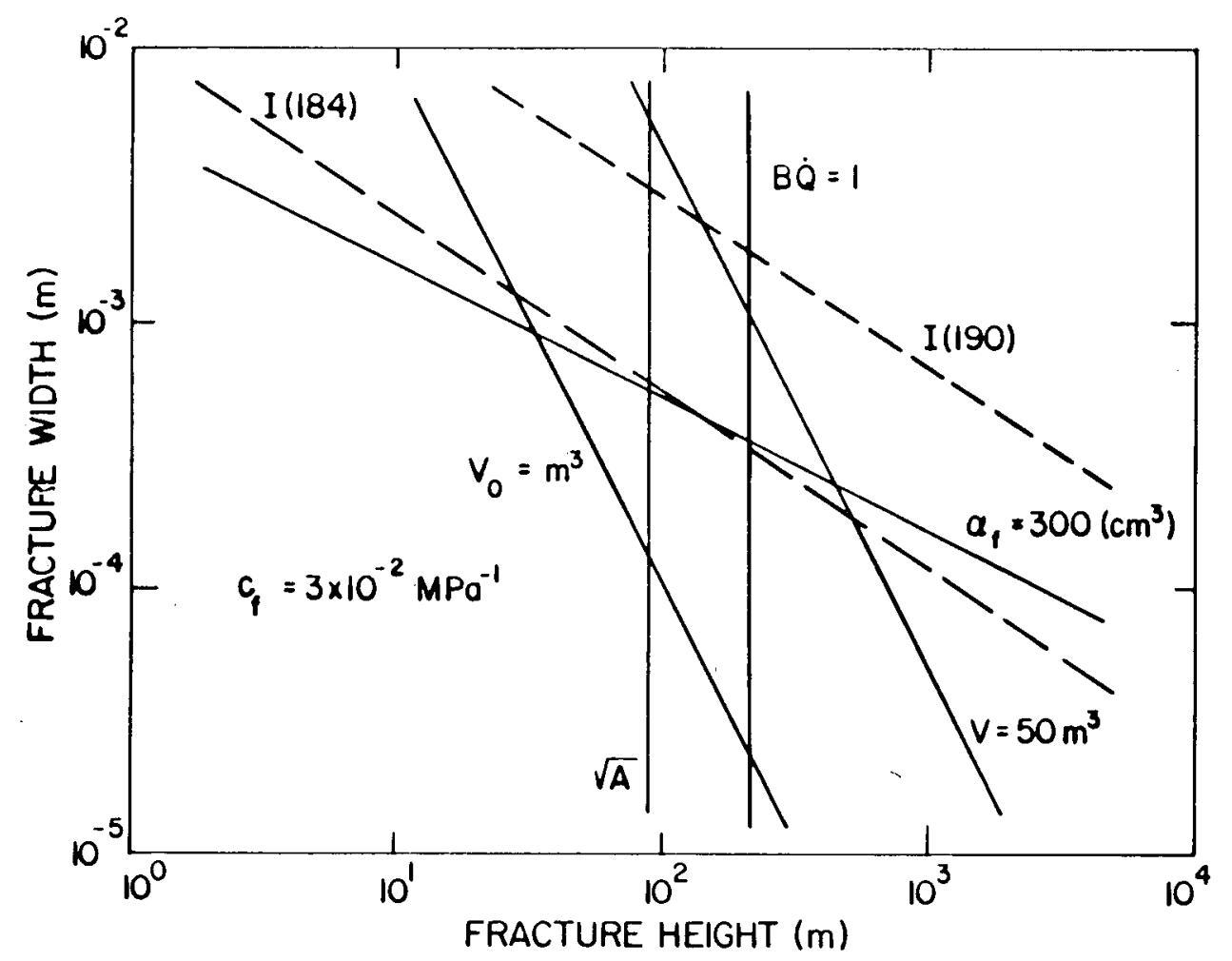

Fig. 13.

Approximate limits on fracture width $(W)$ and fracture height $\left(h_{f}\right)$ set by shortterm injection and flow-through parameters.

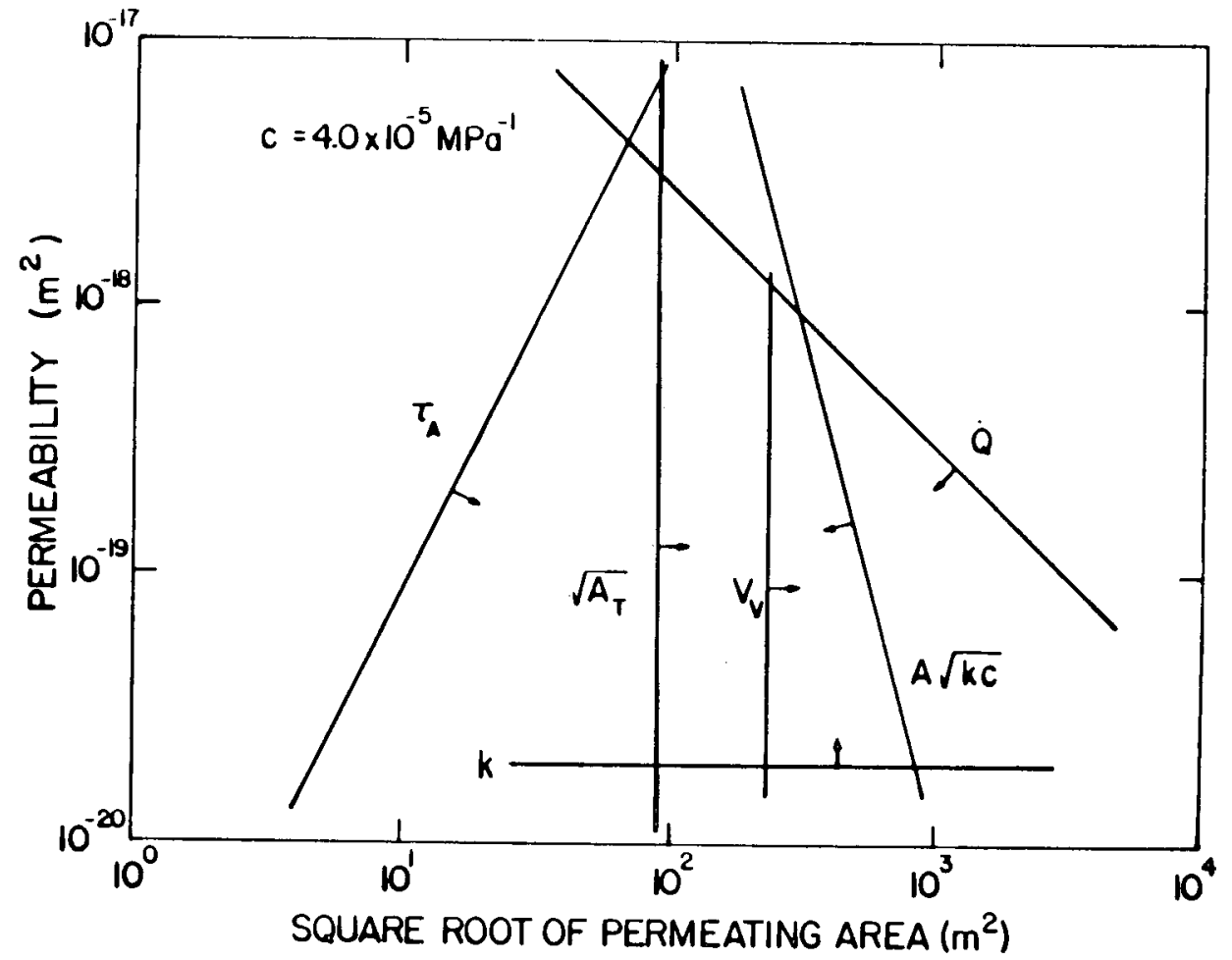

Fig. 14 .

Limits on permeability and fracture area set by long-term flow parameters. 
VII I. NOMENCLATURE

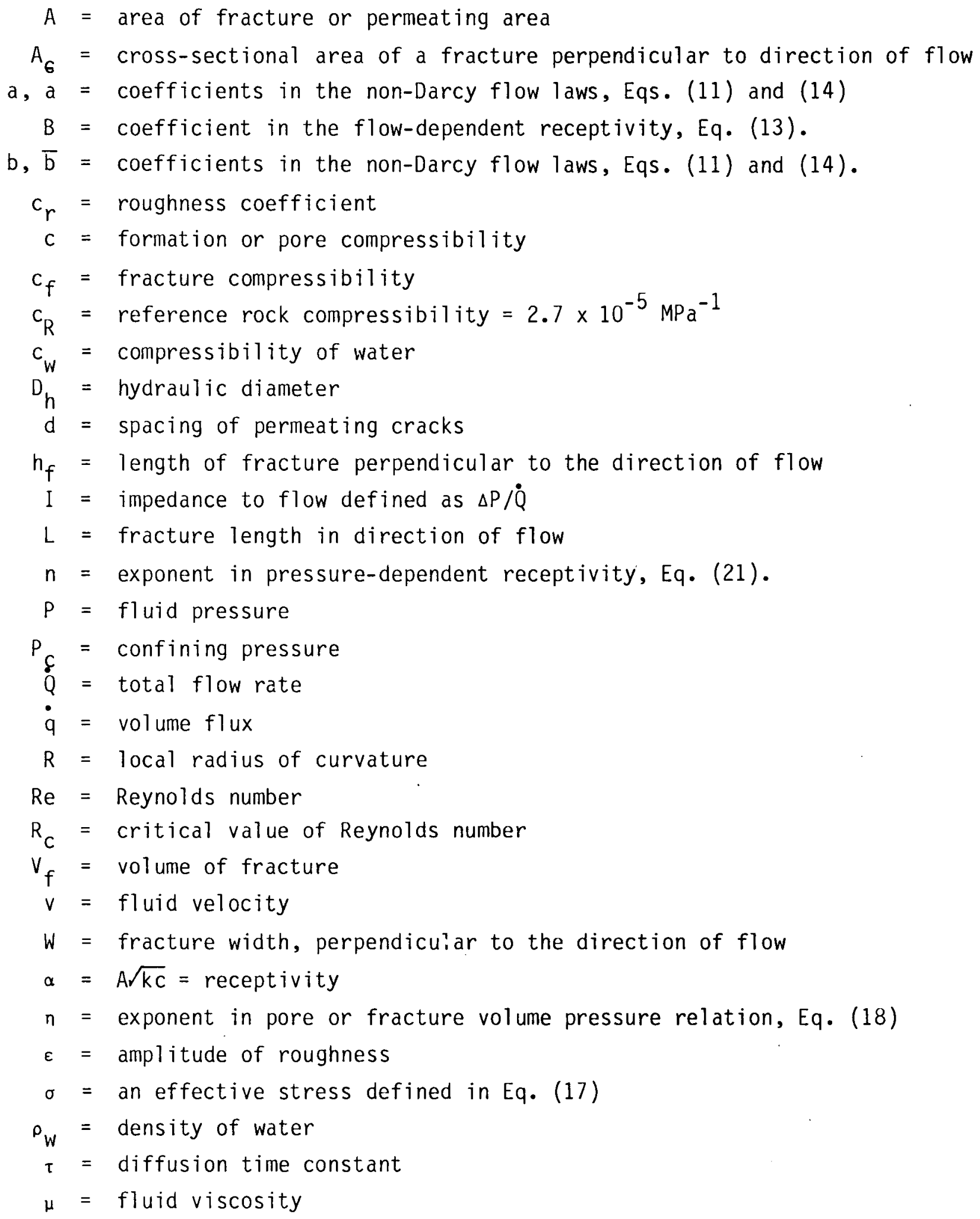




\section{REFERENCES}

1. J. Bear, Dynamics of Fluids in Porous Media, (Elsevier Publishing Company, Amsterdam, 1975).

2. A. G. Blair, J. W. Tester, and J. J. Mortensen, "LASL Hot Dry Rock Geothermal Project, July 1, 1975-June 30, 1976," Los Alamos Scientific Laboratory report LA-6525-PR (0ctober 1976).

3. H. Murphy, R. G. Lawton, J. W. Tester, R. M. Potter, D W. Brown, and R. L. Aamodt, "Preliminary Assessment of a Geothermal Energy Reservoir Formed by Hydraulic Fracturing," Soc. Pet. Eng. 17, 317-326 (August 1977).

4. H. N. Fisher, "An Interpretation of the Pressure and Flow Data for the Two Fractures of the Los Alamos Hot Dry Rock (HDR) Geothermal System," Proc. of the 18th U.S. Symposium on Rock Mechanics, Keystone, C0., (Jure $22,1977)$.

5. LASL HDR Project Staff, "Hot Dry Rock Geothermal Energy Development Project, Annual Report, Fiscal Year 1977," Los Alamos Scientific Laboratory report LA-7109-PR (February 1978).

6. M. C. Brown, R. B. Duffield, C. L. B. Siciliano, and M. C. Smith, "Hot Dry Rock Geothermal Energy Development Program, Annual Report Fiscal Year 1978," Los Alamos Scientific Laboratory report LA-7807-HDR (April 1979).

7. R. Trice, and N. Warren, "Preliminary Study on the Correlations of Acoustic Velocity and Permeability in Two Granodiorites from the LASL Fenton Hill Deep Borehole," Los Alamos Scientific Laboratory report LA-6851-MS (July 1977).

8. J. M. Potter, "Experimental Permeability Studies at Elevated Temperature and Pressure of Granite Rocks," Los Alamos Scientific Laboratory report LA-7224-T (May 1978).

9. C. J. Duffy, "Permeability, Porosity, and Pore Compressibility" in "Hot Dry Rock Geothermal Energy Development Program Annual Report Fiscal Year 1978," Los Alamos Scientific Laboratory report LA-7807-HDR, 63-68 (April, 1979).

10. P. A. Witherspoon, C. H. Amick, and J. E. Gale, "Stress-Flow Behavior of a Fault Zone with Fluid Injection and Withdrawal, "University of California, Report No. 77-1 (May 1977).

11. R. L. Kranz, A. D. Frankel, T. Engelder, and C. H. Scholz, "The Permeability of Whole and Jointed Barre Granite," Int. J. Rock Mech. Min. Sci. and Geomech. Abstr., 16, 225-234 (August 1979).

12. H. R. Pratt, H. S. Swolfs, W. F. Brace, A. D. Black, and J. W. Handin, "Elastic and Transport Properties of an In Situ Jointed Granite," Int. J. Rock Mech. Min. Sci. and Geomech. Abstr., 14, 35-45 (1977).

13. R. G. Lawton, "The AYER Heat conduction Computer Program," Los Al amos Scientific Laboratory report LA-5613-MS (May 1974). 
14. J. W. Tester, and J. N. Albright (eds.), "Hot Dry Rock Energy Extraction Field Test: 75 Days of Operation of a Prototype Reservoir at Fenton Hill," Los Alamos Scientific Laboratory report LA-7771-MS (April 1979).

15. D. W. Brown, "Results of Expt. 186, The High Back-pressure Flow Experiment," (in preparation).

16. C. Louis, "A Study of Ground Water Flow in Jointed Rock and Its Influence on the Stability of Rock Masses," Imperial College of Science and Technology, University of London (1969).

17. A. E. Scheideger, The Physics of Flow Through Porous Media, 3rd ed., (University of Toronto Press, 1974).

18. H. Schlicting, Boundary Layer Theory, 6th ed., (McGraw-Hill Book Company, Inc., New York, 1968).

19. J. W. Tester, R. M. Potter, and R. L. Bivins, "Interwell Tracer Analyses of a Hydraulically Fractured Granite Geothermal Reservoir," paper SPE 8270 presented at SPE-AIME 54 th Annual Fall Technical Conference and Exhibition, Las Vegas, NV (Sept. 23-26, 1979). 


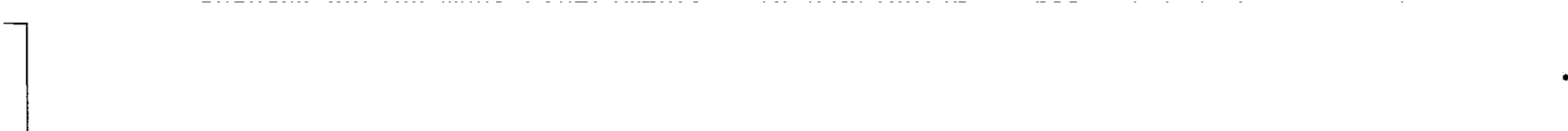

. 


\begin{tabular}{|c|c|c|c|c|c|c|c|c|c|c|c|}
\hline \multirow[b]{2}{*}{ Page Range } & \multicolumn{7}{|c|}{$\begin{array}{l}\text { Printed in the United States of America } \\
\text { Available from } \\
\text { National Technical Information Service } \\
\text { US Department of Commerce } \\
\text { 5285 Port Royal Road } \\
\text { Springfield, VA } 22161\end{array}$} & \multirow{2}{*}{\multicolumn{2}{|c|}{$\begin{array}{c}\text { NTIS } \\
\text { Price Code } \\
\end{array}$}} & \multirow[b]{2}{*}{$\begin{array}{c}\text { Domestic } \\
\text { Price }\end{array}$} & \multirow[b]{2}{*}{$\begin{array}{c}\text { NTIS } \\
\text { Price Code }\end{array}$} \\
\hline & $\begin{array}{c}\text { Domestic } \\
\text { Price }\end{array}$ & $\begin{array}{c}\text { NTIS } \\
\text { Price Code } \\
\end{array}$ & Page Range & $\begin{array}{c}\begin{array}{c}\text { Domestic } \\
\text { Price }\end{array} \\
\end{array}$ & $\begin{array}{l}\text { Microfiche } \\
\text { NTIS } \\
\text { Price Code } \\
\end{array}$ & $3.50(\mathrm{~A} 01)$ & $\begin{array}{c}\begin{array}{c}\text { Domestic } \\
\text { Price }\end{array} \\
\end{array}$ & & & & \\
\hline $001-025$ & S 5.00 & A02 & $151-175$ & $\$ 11.00$ & A08 & $301-325$ & $\$ 17.00$ & A14 & $451-475$ & $\$ 23.00$ & A20 \\
\hline $026-050$ & 6.00 & $\mathrm{~A} 03$ & $176-200$ & 12.00 & A09 & $326-350$ & 18.00 & Als & 476.500 & 24.00 & A21 \\
\hline $051-075$ & 7.00 & A 04 & $201-225$ & 13.00 & A 10 & 351.375 & 19.00 & A16 & 501.525 & 25.00 & A22 \\
\hline $076 \cdot 100$ & 8.00 & A05 & $226-250$ & 14.00 & All & $376-400$ & 20.00 & A 17 & $526-550$ & 26.00 & A 23 \\
\hline $101-125$ & 9.00 & A06 & $251-275$ & 15.00 & A12 & $401-425$ & 21.00 & A18 & 551.575 & 27.00 & A24 \\
\hline \multirow[t]{2}{*}{$126-150$} & 10.00 & A07 & $276-300$ & 16.00 & A13 & $426-450$ & 22.00 & A19 & $576-600$ & 28.00 & A25 \\
\hline & & & & & & & & & $601 \cdot$ up & $\dagger$ & A99 \\
\hline
\end{tabular}


40) 